\title{
3
}

\section{A VAR Analysis of Economic Interdependence: Canada, the United States, and the Rest of the World}

John Kuszczak

John D. Murray

$\Gamma$ his chapter uses the techniques of vector autoregression analysis to investigate the international transmission of business cycles among the major industrialized countries which comprise the G-7. ${ }^{1}$ Particular attention is given to the dynamic behavior and interactions of the U.S. and Canadian economies during the past twenty years. Though several recent papers have questioned the reliability and usefulness of VAR analysis, ${ }^{2}$ the approach would seem to provide a natural and convenient means of (1) measuring the relative importance of domestic and foreign shocks on the evolution of certain key macro variables and (2) comparing the effectiveness of various policy actions under fixed and flexible exchange rate regimes-the two principal objectives of the present chapter.

The chapter begins with an analysis of three closed economy models: Canada, the United States, and Rest of World (ROW). The latter is an aggregate system representing the countries in the G-7 excluding the United States. The regression results, impulse responses, and variance decompositions for these three closed economy models are then compared to three open economy models in which foreign output, prices, interest rates, money, and exchange rates are allowed to affect the domestic economies.

The major conclusions of the chapter can be summarized as follows:

1. Foreign variables exert an important and statistically significant influence on the economies of Canada, the United States, and ROW. Closed econ-

The views expressed in this chapter are those of the authors. No responsibility for them should be attributed to the Bank of Canada. The authors would like to acknowledge the invaluable assistance of Paul Gomme, their research assistant at the Bank of Canada, and Tracey Bartzak, a secretary at the Woodrow Wilson School of Public and International Affairs, Princeton University. They would also like to thank their colleagues for many helpful suggestions, and absolve them of any responsibility for the analysis which follows. 
omy models excluding international influences are therefore likely to give a distorted view of the macroeconomic relationships in these economies and could misrepresent the strength and effectiveness of domestic policy actions.

2. While the Canadian economy is evidently more open than the U.S. economy, and therefore more vulnerable to external shocks, at least 20 to 30 percent of the forecast variance of U.S. output and prices can be attributed to innovations in foreign variables.

3. The money equations for both Canada and the United States are very sensitive to movements in foreign interest rates and exchange rates. Due to the astructural nature of VAR models, however, it is impossible to determine whether this sensitivity is caused by currency substitution on the part of private agents (demand-side effects) or the policy actions of monetary authorities (supply-side effects).

4. Over most of the 1962-84 period, Canadian interest rates and money have moved primarily in response to U.S. shocks. This dependence could have been caused by the tight structural relationships binding the U.S. and Canadian economies, or alternatively what Richard Cooper (1985) has termed "goal and policy interdependence."

5. Finally, as an empirical matter the distinction between fixed and flexible exchange rate systems does not seem to have been very important over the 1962-84 period. Tests for structural stability suggest that the time series behavior of Canadian, U.S., and ROW variables remained virtually unchanged following the move to flexible exchange rates in the early 1970 s.

The remainder of the chapter is divided into six sections. The first briefly discusses the VAR methodology and the structure of the closed and open economy models. The next describes the data series used in the Canadian and U.S. regressions as well as the trade-weighted indexes that were constructed to estimate for the ROW models. The regression results and variance decompositions of the models are presented in the following section, along with graphs of the impulse responses for selected domestic and foreign shocks. Next comes an examination of the policy implications of our empirical work. The chapter concludes with a brief summary and some suggestions for future research.

\section{Models and Methodology}

Two sets of linear, constant coefficient VAR models are estimated in the empirical portion of this chapter. The first set contains three closed economy models representing Canada, the United States, and the rest of the world, 
respectively. Each closed economy model has four endogenous variablesoutput, prices, money, and interest rates-which are regressed on a constant term, their own lagged values, and lagged values of the other three endogenous variables in the system. ${ }^{3}$ The complete four-equation system for each country can be written in vector notation as

$$
y_{t}^{i}=\alpha+\sum_{k=1}^{n} \beta(k) y_{t-k}^{i}+\epsilon_{t}
$$

where $y_{t}^{i}$ is a $4 \times 1$ vector of endogenous variables for country $i, \alpha$ is a $4 \times 1$ vector of constant terms, $\beta(k)$ is a $4 \times 4$ matrix of estimated coefficients on the lagged values of $y_{t}$, and $\epsilon_{t}$ is a white noise error term assumed to be independent and normally distributed with zero mean.

The second set of models has the same basic structure as the first but includes five extra variables: foreign output, prices, money, interest rates, and an exchange rate. These augmented open economy models represent the most important part of our analysis. They are compared to the more familiar closed economy models in the Results section and are used to test the statistical significance and economic importance of foreign variables in the three domestic economies.

The structure of the open economy models will vary according to the relationship that the domestic and foreign economies bear to one another. If the international system is truly interdependent, such that shocks to economy $A$ impact on economy $B$ and vice versa (bidirectional causality), the vector $y_{t-k}$ in equation 3.1 will include all nine endogenous variables (four domestic and five foreign). $\beta(k)$, the matrix of parameters on lagged values of $y$, will also be expanded from dimension $4 \times 4$ to $9 \times 9$ and will contain few, if any, zero elements. If, on the other hand, the relationship between $A$ and $B$ is best described as one of dependence as opposed to interdependence, lagged values of $y$ from the small (dependent) economy will have no impact on the large economy and at least $5 \times 5$ of the coefficients in the $\beta(k)$ matrix of the large economy will have zero values.

All of the models described here have traditional VAR structures in the sense that (1) they impose a common lag length on all explanatory variables, (2) they include the same explanatory variables in each equation, and (3) they use only lagged values of the endogenous variables and a constant term as regressors. This symmetric structure makes it possible to obtain consistent and efficient coefficient estimates by running ordinary least squares on the individual equations, provided the error terms in equation 3.1 are not autocorrelated. One can thereby avoid the necessity of costly systems estimation. The absence of contemporaneous variables on the right side of the equations also eliminates the need to make arbitrary assumptions about the causal relationships of the variables. ${ }^{4}$

There are some notable disadvantages associated with this unrestricted 
form of econometric analysis, however. First, traditional VAR models are very data intensive. Since the number of coefficients that have to be estimated expands by a factor of $n(2 j+1)+1$ for every additional variable in the model, we are forced to use very parsimonious specifications. ${ }^{5}$ As a consequence, several potentially important variables could be omitted. Second, by admitting only lagged endogenous variables on the right-hand side of each equation (in addition to a constant term), all the contemporaneous shocks which impact on $y_{t}$ are forced to feed through the residuals, $\epsilon_{t}$. While this may not pose a problem in the estimation stage of the analysis, the impulse responses and variance decompositions derived from these initial estimates could be seriously affected. If the residuals have high contemporaneous correlations, any adjustment to the order in which the variables are entered in the system could produce dramatic changes in the results. More specifically, certain variables could assume exaggerated importance in the variance decompositions, while other, more significant variables receive little or no weight. This problem arises because the Choleski decomposition which is used to convert the VAR models into their moving average representations attributes all the contemporaneous correlation between two series to the variable that is ordered first in each model.

Some authors have tried to improve the efficiency of their VAR estimates and to save degrees of freedom by assigning different lag lengths to the various regressors. Batten and Thorton (1985), Fackler (1985), and others have proposed a number of heuristic algorithms for this purpose, based on the Akaike Final Prediction Error criterion. Unfortunately these techniques are very cumbersome when more than two or three variables are involved, and typically yield results that are very sample sensitive.

Given the number of models to be estimated here and the large number of variables contained in each, selective adjustment of the lags on individual variables did not seem to be a very practicable approach. Instead, we have tried to keep our models as small as possible by running systemwide significance tests on alternative lag lengths for all the variables in each model. While the lag lengths that are ultimately assigned to the models are probably too long for some series and too short for others, there does not seem to be any obvious alternative to this more aggregative approach.

The second problem mentioned above, concerning the sensitivity of variance decompositions to the ordering of the variables, can be addressed in a somewhat more satisfactory fashion using a strategy recommended by Doan and Litterman (1980). By inspecting the contemporaneous correlations of the residuals in each model it is possible to identify variable combinations that could pose a problem. The variance decompositions and impulse responses can then be recomputed, switching the order of any variables that are highly correlated in order to check the sensitivity of the results. In none of the cases to be reported here did this appear to be a major problem. 


\section{Data}

In order to implement the VAR modeling techniques and test procedures described under Models and Methodology, suitable real world proxies must be found for all the domestic and foreign variables in the models. Though several alternative measures were initially considered, in the end most had to be rejected because they were either not available for all countries or only extended over short time periods. The series which were finally chosen are shown below, along with their mnemonics: ${ }^{6}$

Output $=$ seasonally adjusted index of industrial production $(U)$

Prices $=$ seasonally adjusted consumer price index $(P)^{7}$

Money $=$ seasonally adjusted demand deposits plus currency $(M)$

Interest rate $=$ call loan rate on money market instruments $(R)$

Exchange rate $=$ price of foreign currency in U.S. dollars $(S)$

All of the series have been defined on a quarterly basis and typically run from 1964.1 to 1984.4. Data for Canada and the United States, however, have been extended back to 1960.1 .

Representative aggregate measures of output, prices, money, and the exchange rate were constructed for ROW by combining individual series for Canada, France, Germany, Italy, Japan, and the United Kingdom in four trade-weighted indexes. ${ }^{8}$ The specification used to aggregate the series can be written as

$$
X_{w, t}=X_{w, t-1} \prod_{i=1}^{6}\left(X_{i, t} / X_{i, t-1}\right) \tilde{S}_{i, t}
$$

where:

$$
\begin{aligned}
X_{w}= & \text { index of aggregate output (prices, money, and the exchange rate) } \\
& \text { for ROW } \\
X_{i}= & \text { aggregate output (prices, money, and the exchange rate) for the } \\
& i \text { th country } \\
\tilde{S}_{i}= & i \text { th country's share of world trade }
\end{aligned}
$$

The share weights, $\tilde{S}_{i, t}$, reflect the relative importance of each country in world trade and have been defined such that

$$
\sum_{i=1}^{6} \tilde{S}_{i, t}=1
$$

The quarterly values of $\tilde{S}_{i, t}$, which are included in equation 3.2 were obtained by fitting a polynomial time series to annual data extracted from the Inter- 
82 - How Open Is the U.S. Economy?

national Monetary Fund's World Trade Statistics. Their average values over the 1964.1-1984.4 sample period are reported below. ${ }^{9}$
$\frac{\text { Canad }}{0.12}$
$\frac{\text { France }}{0.16}$
$\frac{\text { Germany }}{0.26}$
$\frac{\text { Italy }}{0.12}$
$\frac{\text { Japan }}{0.15}$
U.K.
0.19

The index constructed for ROW interest rates uses the same tradeweights as equation 3.2 but has a simpler, linear specification

$$
R_{w, t}=\sum_{i=1}^{5} \tilde{S}_{i, t}^{\prime}\left(R_{i, t}\right)
$$

Only five countries were included in equation 3.3 as reliable interest rate data were not available for Italy prior to 1975 .

One final point that should be mentioned regarding the data concerns the procedures used to render the series stationary. VAR analysis assumes that all the stochastic processes in the autoregressive system are variance-covariance stationary. If this condition is not met, little confidence can be placed in the VAR regression results. Since most, if not all, of the data here are highly autocorrelated and tend to drift over time, some form of detrending is obviously required before the models can be estimated.

The two most popular methods of detrending are (1) regressing the data on time (or a function of time), and (2) differencing the data. A priori it is not clear which method is more appropriate, but using the wrong approach could have serious consequences for the empirical work that follows.

After considering various alternatives we eventually decided to transform the data into first-differences of their natural logarithms (which is roughly equivalent to using percentage changes. $)^{10}$ Our choice was influenced in part by recent work by Nelson and Plosser (1982). Using a test developed by Dickey and Fuller (1979), the authors have shown that most U.S. time series are well represented as difference stationary processes. In addition, they have found that data that are detrended with time, as opposed to being first differenced, often produce "spurious regression results."11

\section{Results}

\section{Closed Economy Models}

The results for the closed economy models will not be discussed in much detail since there is reason to believe that the models are seriously misspecified. The significance tests reported below show that they exclude several important foreign variables. Nevertheless, these restricted four-equation models do provide useful control solutions which can be used to test the open 
Table 3-1

Testing the Lag Structures of Closed Economy Models, 1962.1-1984.4

Canada:

1962.3-1984.4

8 vs. 6 lags

$\chi^{2}(32)^{\mathrm{a}} 528.5$

Accept 6

6 vs. 4 lags

$\chi^{2}(32)=47.6^{*}$

Reject 4

United States:

1962.1-1984.4

8 vs. 6 lags

6 vs. 4 lags

$\chi^{2}(32)=36.3$

Accept 6

$\chi^{2}(32)=72.7^{*}$

Reject 4

Rest of World:

1965.3-1984.4

8 vs. 6 lags

6 vs. 4 lags

4 vs. 3 lags

3 vs. 2 lags

$\chi^{2}(32)=28.7$

Accept 6

$\chi^{2}(32)=26.0$

Accept 4

$\chi^{2}(16)=16.0$

Accept 3

2 vs. 1 lags

$\chi^{2}(16)=21.0$

Accept 2

$\chi^{2}(16)=27.8^{*}$

Reject 1

${ }^{2}$ Likelihood ratio test statistic distributed as $\chi^{2}$ with $(r)$ degrees of freedom.

* Significant at the 5.0 percent level.

economy results discussed under Open Economy Models. The results are also of some interest in their own right since most of the VAR analyses published to date employ similar closed economy specifications and readers may wish to compare their results with those here.

Parameter Estimates. The first stage of this analysis involves selecting an appropriate lag length for the (endogenous) explanatory variables in each model. As noted earlier, this is done on a systemwide basis (the whole model is tested as opposed to individual equations or variables), using a modified likelihood ratio test first proposed by Sims (1980b). ${ }^{12}$ The results are reported in table $3-1$.

The lag lengths assigned to the Canadian and U.S. models are much longer than those assigned to the ROW model (six lags versus two). This difference might be explained by the aggregation procedure that was used to create the ROW variables. Averaging the data across six different countries may have removed some of the variation that made longer lags necessary in the other models.

Parameter estimates and summary statistics for the final versions of the closed economy models are presented in tables 3-2 through 3-4. ${ }^{13}$ Though it is often difficult to interpret the coefficients in VAR models, plausible stories can be told for most results here. 
84 - How Open Is the U.S. Economy?

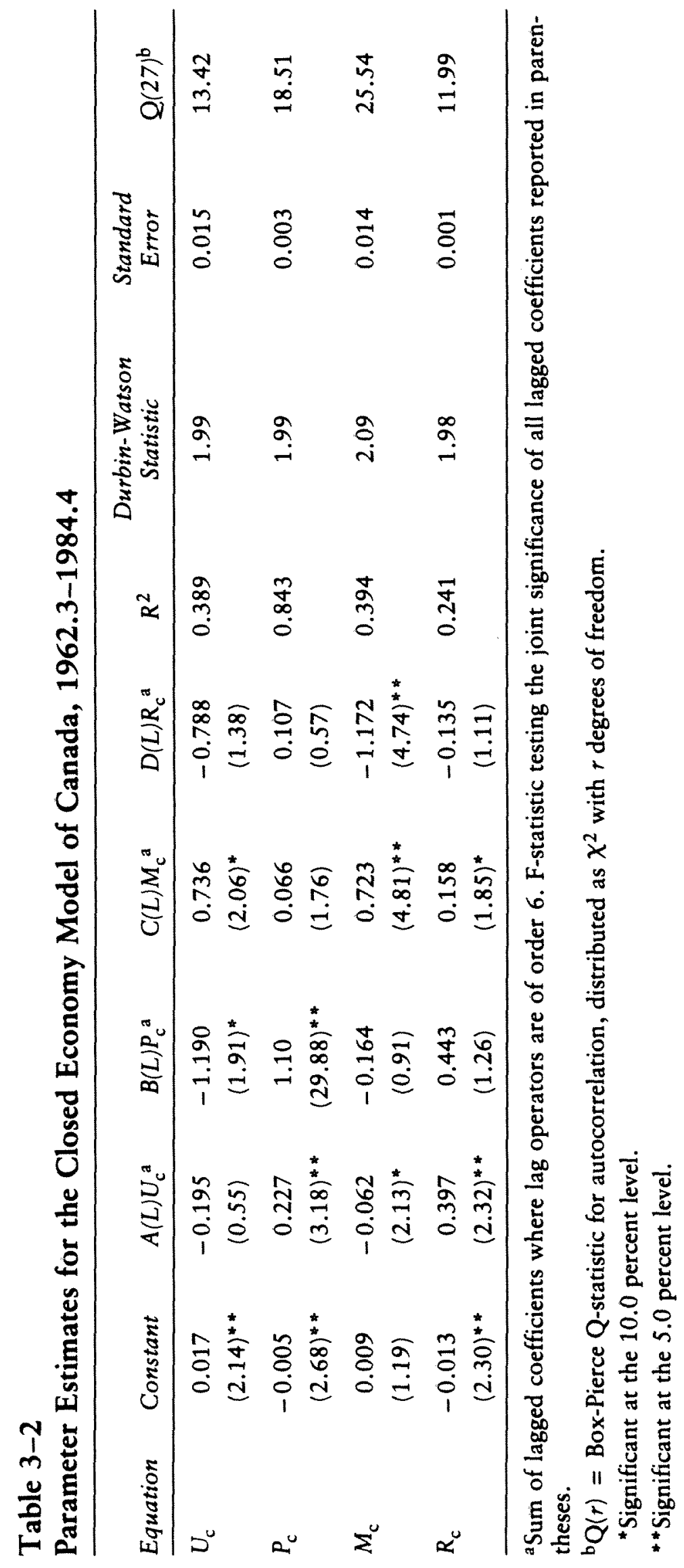




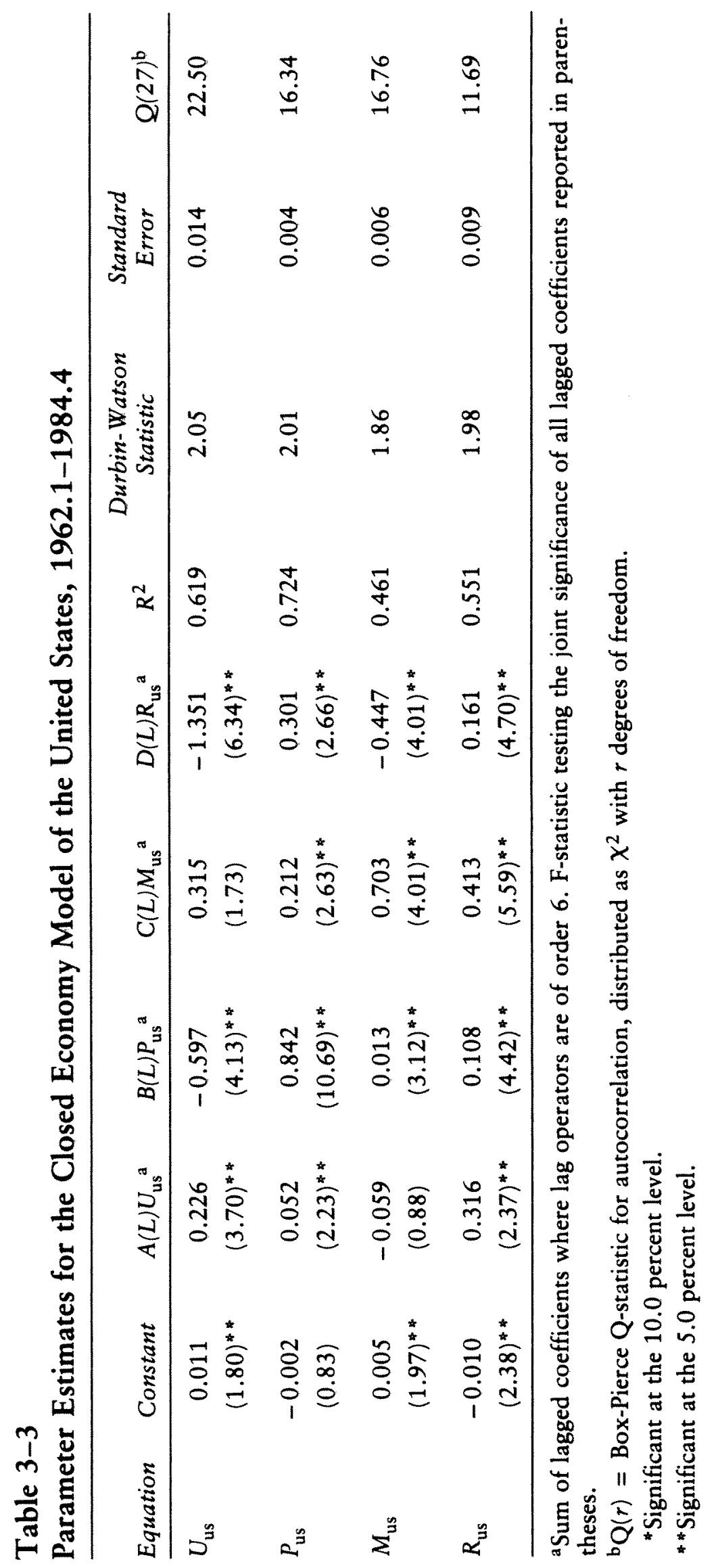


86 How Open Is the U.S. Economy?

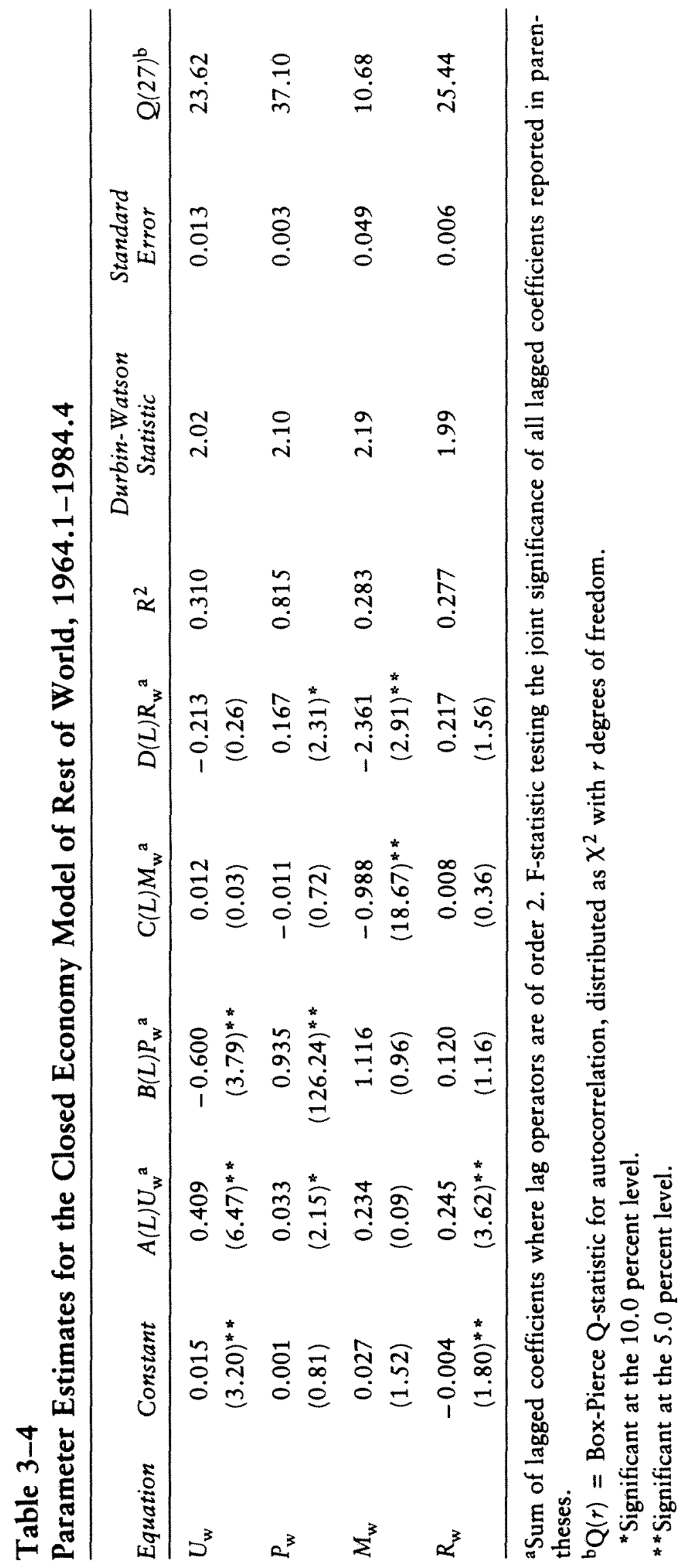


Real growth $(U)$ is negatively related to increases in interest rates and inflation, ${ }^{14}$ and is positively related to money growth and its own lagged values, except in Canada where lagged values of $U_{c}$ bear a negative but statistically insignificant relationship to current real growth. Inflation on the other hand is positively related to interest rates and lagged inflation, as well as output and money growth-at least in Canada and the United States. The positive sign on lagged interest rates in the Canadian and U.S. price equations is somewhat unexpected, but the same response has been recorded elsewhere by Sims (1980a) and Litterman and Weiss (1983). The result can be interpreted in terms of a Fischer effect (nominal interest rates correctly anticipating future inflation) and/or what Driskill and Sheffrin (1985) have recently labeled a "Patman effect." The latter refers to the direct cost-push effect that higher interest rates might have on prices.

Money growth $(M)$ is depressed by higher interest rates in all three "countries" and generally bears a positive relationship to its own lagged values. $M_{\mathrm{w}}$ in the ROW model is the sole exception. Interest rates $(R)$ tend to rise with higher real growth, inflation, and money, but the relationships are often not statistically significant.

The only troublesome result in tables $3-2,3-3$, and 3-4 is the negative and statistically significant coefficient on $U_{c}$ in the Canadian money equation. ${ }^{15}$ For the most part, however, the qualitative results are very similar across all three models. There are nevertheless two intercountry differences that deserve special attention.

First, the U.S. equations seem to contain more significant variables and generally have greater explanatory power than either the Canadian or ROW equations. This could be taken as evidence that the closed economy specification is more acceptable in the case of the United States, though clearly it is impossible to make any direct comparisons as one is dealing with different dependent variables in each equation. Second, money and interest rates have much less influence in the ROW than in the United States. While this could be a consequence of aggregation, it could also reflect the more heavily regulated nature of Japanese and European financial markets.

Variance Decomposition and Impulse Responses. The variance decompositions of the closed economy models are reported in tables 3-5, 3-6, and 3-7. The statistics measure the proportion of the error variance in each domestic variable that can be attributed to shocks (or "innovations") in output, prices, money, and interest rates over forecast horizons ranging from one to twelve quarters. As one might expect, the most important shocks come from lagged values of the dependent variables themselves. Nevertheless, shocks from other variables typically account for a significant proportion of the error variance in each variable by the twelfth quarter. The one exception is $M_{\mathrm{w}}$ (see table 3-7), which is virtually exogenous. ${ }^{16}$ 
88 - How Open Is the U.S. Economy?

Table 3-5

Canada: Variance Decomposition of Prediction Errors

\begin{tabular}{|c|c|c|c|c|c|c|}
\hline \multirow[b]{2}{*}{ Variable } & \multirow[b]{2}{*}{ Quarter } & \multicolumn{4}{|c|}{ Proportion of Error Attributed to Shocks in: } & \multirow{2}{*}{$\begin{array}{c}\text { Standard } \\
\text { Error }\end{array}$} \\
\hline & & $U_{\mathrm{c}}$ & $P_{c}$ & $M_{c}$ & $R_{\mathrm{c}}$ & \\
\hline \multirow[t]{4}{*}{$U_{c}$} & 1 & 100.0 & 0.0 & 0.0 & 0.0 & $0.124-01$ \\
\hline & 4 & 85.5 & 4.6 & 5.1 & 4.8 & $0.136-01$ \\
\hline & 8 & 78.3 & 8.8 & 5.5 & 7.3 & $0.170-01$ \\
\hline & 12 & 69.2 & 8.7 & 9.4 & 12.7 & $0.181-01$ \\
\hline \multirow[t]{4}{*}{$P_{\mathrm{c}}$} & 1 & 0.2 & 93.8 & 5.6 & 0.4 & $0.287-02$ \\
\hline & 4 & 6.0 & 62.3 & 25.5 & 6.3 & $0.476-02$ \\
\hline & 8 & 9.0 & 48.7 & 31.5 & 10.8 & $0.612-02$ \\
\hline & 12 & 7.1 & 36.8 & 38.3 & 17.8 & $0.730-02$ \\
\hline \multirow[t]{4}{*}{$M_{c}$} & 1 & 0.0 & 0.0 & 94.3 & 5.7 & $0.116-01$ \\
\hline & 4 & 13.5 & 3.2 & 59.0 & 24.2 & $0.155-01$ \\
\hline & 8 & 16.1 & 4.3 & 56.4 & 23.2 & $0.168-01$ \\
\hline & 12 & 15.8 & 5.3 & 54.5 & 24.5 & $0.173-01$ \\
\hline \multirow[t]{4}{*}{$R_{\mathrm{c}}$} & 1 & 10.5 & 0.0 & 0.0 & 89.5 & 0.867 \\
\hline & 4 & 18.8 & 3.3 & 7.1 & 70.8 & 1.060 \\
\hline & 8 & 20.9 & 4.6 & 10.3 & 64.2 & 1.135 \\
\hline & 12 & 20.7 & 4.9 & 10.6 & 63.7 & 1.158 \\
\hline
\end{tabular}

Note: Equations were estimated over the sample period 1962.3-1984.4 with six lags on each explanatory variable. The order of the variables in the variance decompositions was $U, R, M$, and $P$.

In order to test the sensitivity of these results to changes in the ordering of the variables, the variance decompositions were rerun reversing the positions of those variables that were most highly correlated. The only variables affected were $R-U$ in the case of Canada and the United States, and $R-U$ and $R-P$ in the ROW (see table 3-8). Since the results did not change significantly after the variables were reordered, they will not be reported here. Evidently, the residual correlations must be much higher than those recorded in table 3-8 before any major changes will appear in the variance decompositions.

The impulse responses for the closed economy models are shown in figures 3-1 through 3-4. Each figure contains three plots, representing the responses of Canadian (----), U.S. (- - - ), and ROW (-) variables to innovations in $U, R, M$, and $P$. The adjustment paths are all dynamically 
Table 3-6

United States: Variance Decomposition of Prediction Errors

\begin{tabular}{|c|c|c|c|c|c|c|}
\hline \multirow[b]{2}{*}{ Variable } & \multirow[b]{2}{*}{ Quarter } & \multicolumn{4}{|c|}{ Proportion of Error Attributed to Shocks in: } & \multirow{2}{*}{$\begin{array}{c}\text { Standard } \\
\text { Error }\end{array}$} \\
\hline & & $U_{\text {us }}$ & $P_{\mathrm{us}}$ & $M_{\mathrm{us}}$ & $R_{\mathrm{us}}$ & \\
\hline \multirow[t]{4}{*}{$U_{\mathrm{us}}$} & 1 & 100.0 & 0.0 & 0.0 & 0.0 & $0.117-01$ \\
\hline & 4 & 76.2 & 2.4 & 6.0 & 15.4 & $0.163-01$ \\
\hline & 8 & 60.0 & 7.9 & 13.3 & 18.8 & $0.204-01$ \\
\hline & 12 & 54.6 & 12.4 & 16.1 & 16.9 & $0.219-01$ \\
\hline \multirow[t]{4}{*}{$P_{\mathrm{us}}$} & 1 & 0.2 & 98.8 & 0.1 & 0.9 & $0.381-02$ \\
\hline & 4 & 3.2 & 70.4 & 17.8 & 8.6 & $0.579-02$ \\
\hline & 8 & 6.7 & 60.9 & 25.0 & 7.4 & $0.722-02$ \\
\hline & 12 & 6.4 & 58.0 . & 28.5 & 7.1 & $0.770-02$ \\
\hline \multirow[t]{4}{*}{$M_{\mathrm{us}}$} & 1 & 1.3 & 0.0 & 98.5 & 0.2 & $0.493-02$ \\
\hline & 4 & 8.4 & 4.7 & 77.8 & 9.1 & $0.603-02$ \\
\hline & 8 & 12.4 & 11.5 & 64.8 & 11.4 & $0.698-02$ \\
\hline & 12 & 12.9 & 14.3 & 60.3 & 12.5 & $0.728-02$ \\
\hline \multirow[t]{4}{*}{$R_{\mathrm{us}}$} & 1 & 19.6 & 0.0 & 0.0 & 80.4 & 0.796 \\
\hline & 4 & 20.0 & 9.1 & 17.6 & 53.3 & 1.114 \\
\hline & 8 & 17.0 & 15.0 & 17.6 & 50.4 & 1.252 \\
\hline & 12 & 18.3 & 17.9 & 18.6 & 45.2 & 1.340 \\
\hline
\end{tabular}

Note: Equations were estimated over the sample period 1962.3-1984.4 with six lags on each explanatory variable. The order of the variables in the variance decompositions was $U, R, M$, and $P$.

stable and are similar across the three countries, though the cycles are much smoother in the case of ROW and typically display less variability-a consequence of the shorter lags assigned to the ROW model.

In general the impact and short-run effects of the various shocks are consistent with the parameter estimates in tables 3-2 through 3-4. Output in each country increases in response to positive money shocks and decreases in response to higher prices and interest rates. Notice, however, that the contractionary effects of $R_{\text {us }}$ and $P_{\text {us }}$ on U.S. output are usually delayed by two to three quarters. ${ }^{17}$ Money growth is also reduced by interest rates, but increases in response to positive innovations in prices. Interest rates and prices, on the other hand, typically increase in response to innovations in all four domestic variables.

Despite the consistency and apparent plausibility of most of the results, 
90 - How Open Is the U.S. Economy?

Table 3-7

Rest of World: Variance Decomposition of Prediction Errors

\begin{tabular}{|c|c|c|c|c|c|c|}
\hline \multirow[b]{2}{*}{ Variable } & \multirow[b]{2}{*}{ Quarter } & \multicolumn{4}{|c|}{ Proportion of Error Attributed to Shocks in: } & \multirow{2}{*}{$\begin{array}{c}\text { Standard } \\
\text { Error }\end{array}$} \\
\hline & & $U_{w}$ & $P_{\mathrm{w}}$ & $M_{\mathrm{w}}$ & $R_{\mathrm{w}}$ & \\
\hline \multirow{4}{*}{$U_{\mathrm{w}}$} & 1 & 100.0 & 0.0 & 0.0 & 0.0 & $0.120-01$ \\
\hline & 4 & 91.9 & 4.8 & 0.1 & 3.2 & $0.135-01$ \\
\hline & 8 & 83.6 & 10.5 & 0.2 & 5.7 & $0.145-01$ \\
\hline & 12 & 81.1 & 12.4 & 0.2 & 6.3 & $0.149-01$ \\
\hline \multirow[t]{4}{*}{$P_{\mathrm{w}}$} & 1 & 0.6 & 93.0 & 0.2 & 6.2 & $0.326-02$ \\
\hline & 4 & 13.0 & 68.9 & 0.9 & 17.1 & $0.562-02$ \\
\hline & 8 & 20.2 & 61.0 & 0.8 & 18.1 & $0.715-02$ \\
\hline & 12 & 22.1 & 59.0 & 0.7 & 18.1 & $0.767-02$ \\
\hline \multirow[t]{4}{*}{$M_{\mathrm{w}}$} & 1 & 0.3 & 0.0 & 99.2 & 0.5 & $0.460-01$ \\
\hline & 4 & 0.5 & 0.5 & 95.1 & 3.9 & $0.567-01$ \\
\hline & 8 & 0.8 & 0.7 & 94.6 & 3.9 & $0.571-01$ \\
\hline & 12 & 0.8 & 0.8 & 94.4 & 4.0 & $0.572-01$ \\
\hline \multirow[t]{4}{*}{$R_{\mathrm{w}}$} & 1 & 9.3 & 0.0 & 0.0 & 90.7 & 0.565 \\
\hline & 4 & 33.1 & 0.7 & 0.4 & 65.8 & 0.681 \\
\hline & 8 & 33.1 & 1.7 & 0.5 & 64.8 & 0.690 \\
\hline & 12 & 33.1 & 2.3 & 0.5 & 64.1 & 0.694 \\
\hline
\end{tabular}

Note: Equations were estimated over the sample period 1964.1-1984.4 with two lags on each explanatory variable. The order of the variables in the variance decompositions was $U, R, M$, and $P$.

several notable intercountry differences can be observed in the plots. Canada, for example, is the only country whose prices fall in response to higher interest rates. As well, the response of money to an interest rate shock in Canada and ROW is much higher than that of the United States. This fact has been noted previously by Abrams and Sellon (1983), and was used by the authors to explain Canada's remarkable ability to consistently meet its monetary targets over the $1975-81$ period. ${ }^{18}$

Finally, it is worth noting the negative response of prices in the ROW model to innovations in $M_{\mathrm{w}}$. We are not aware of any generally accepted theory or institutional peculiarity that would explain why prices might fall in response to a positive money shock. Indeed, since the coefficients on $M_{w}$ in the ROW price equation are all statistically insignificant, it would be a mistake to attach much importance to this curious result. We mention it only to 
Table 3-8

Residual Cross-Correlations for the Closed Economy Models

\begin{tabular}{lcccc}
\hline Canada & $U_{\mathrm{c}}$ & $P_{\mathrm{c}}$ & $M_{\mathrm{c}}$ & $R_{\mathrm{c}}$ \\
$U_{\mathrm{c}}$ & 1.000 & & & \\
$P_{\mathrm{c}}$ & -0.048 & 1.000 & & \\
$M_{\mathrm{c}}$ & 0.013 & 0.214 & 1.000 & 1.000 \\
$R_{\mathrm{c}}$ & $0.324^{*}$ & -0.042 & -0.221 & \\
& & & & $R_{\mathrm{us}}$ \\
United States & $U_{\mathrm{us}}$ & $P_{\mathrm{us}}$ & $M_{\mathrm{us}}$ & \\
$U_{\mathrm{us}}$ & 1.000 & & & \\
$P_{\mathrm{us}}$ & -0.048 & 1.000 & & \\
$M_{\mathrm{us}}$ & 0.113 & -0.026 & 1.000 & \\
$R_{\mathrm{us}}$ & $0.442^{*}$ & 0.064 & 0.093 & \\
& & & & \\
Rest of World & $U_{\mathrm{w}}$ & $P_{\mathrm{w}}$ & $M_{\mathrm{w}}$ & \\
$U_{\mathrm{w}}$ & 1.000 & & & \\
$P_{\mathrm{w}}$ & 0.078 & 1.000 & & \\
$M_{\mathrm{w}}$ & 0.053 & -0.052 & 1.000 & \\
$R_{\mathrm{w}}$ & $0.305^{*}$ & $0.261^{*}$ & -0.050 & \\
\hline
\end{tabular}

"Significant at the 5.0 percent level.

highlight another potential problem associated with VAR analysis. Because the impulse responses and variance decompositions are extracted in a simple, mechanistic fashion, without regard to their statistical significance, it is not unusual to obtain a few unexpected results.

\section{Open Economy Models}

Once the five foreign variables are added to the models here, the longest lag length that the equations can reasonably accommodate is four. ${ }^{19}$ This restriction is not binding in any of the regressions, which are run over shorter sample periods beginning in either 1970.3 or 1973.1 , as the models accept lag lengths as short as one or two (see table 3-9). It does pose a problem in the open economy models for Canada and the United States, which are run over longer sample periods beginning in 1962.1 and 1962.3. These models require at least four lags on each explanatory variable. Though we believe that any biases and distortions that result from these constraints are not serious, we have no formal means of testing their significance. 

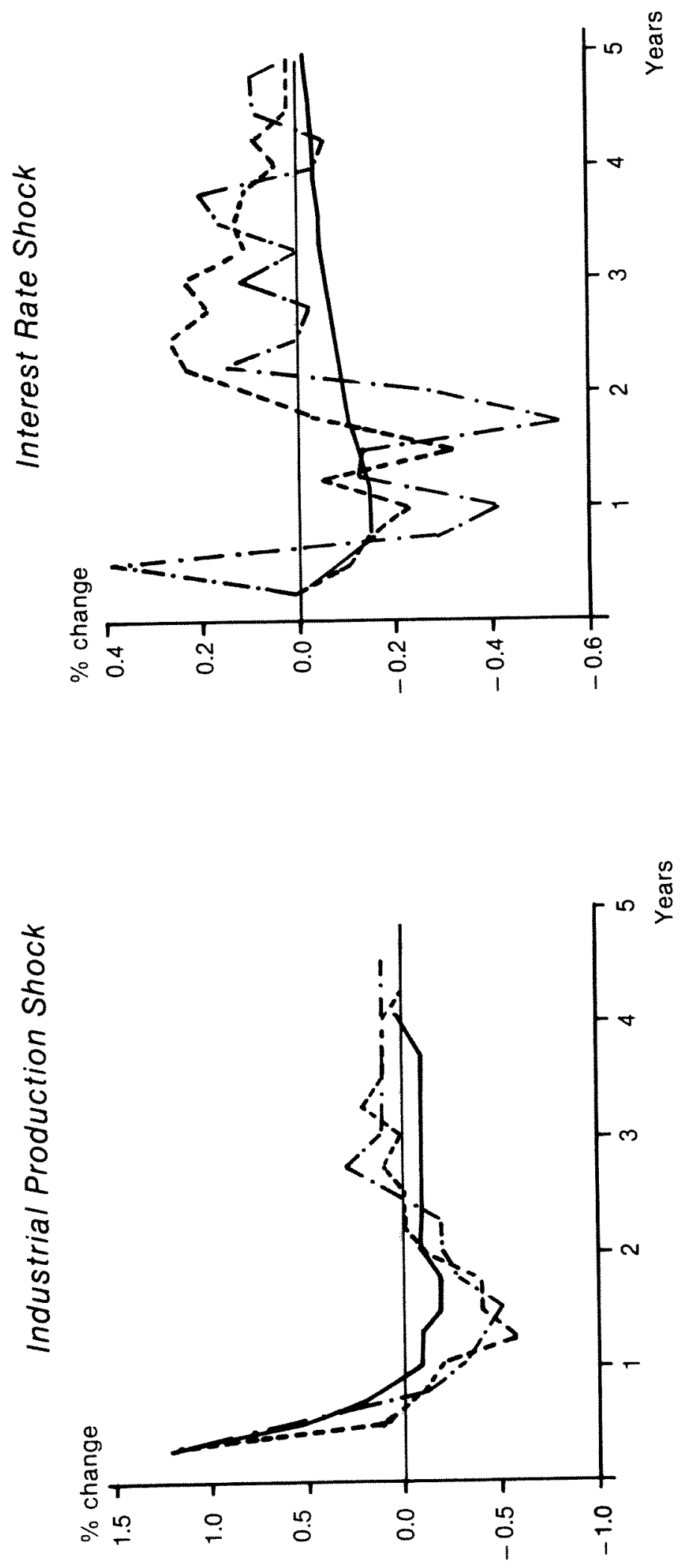

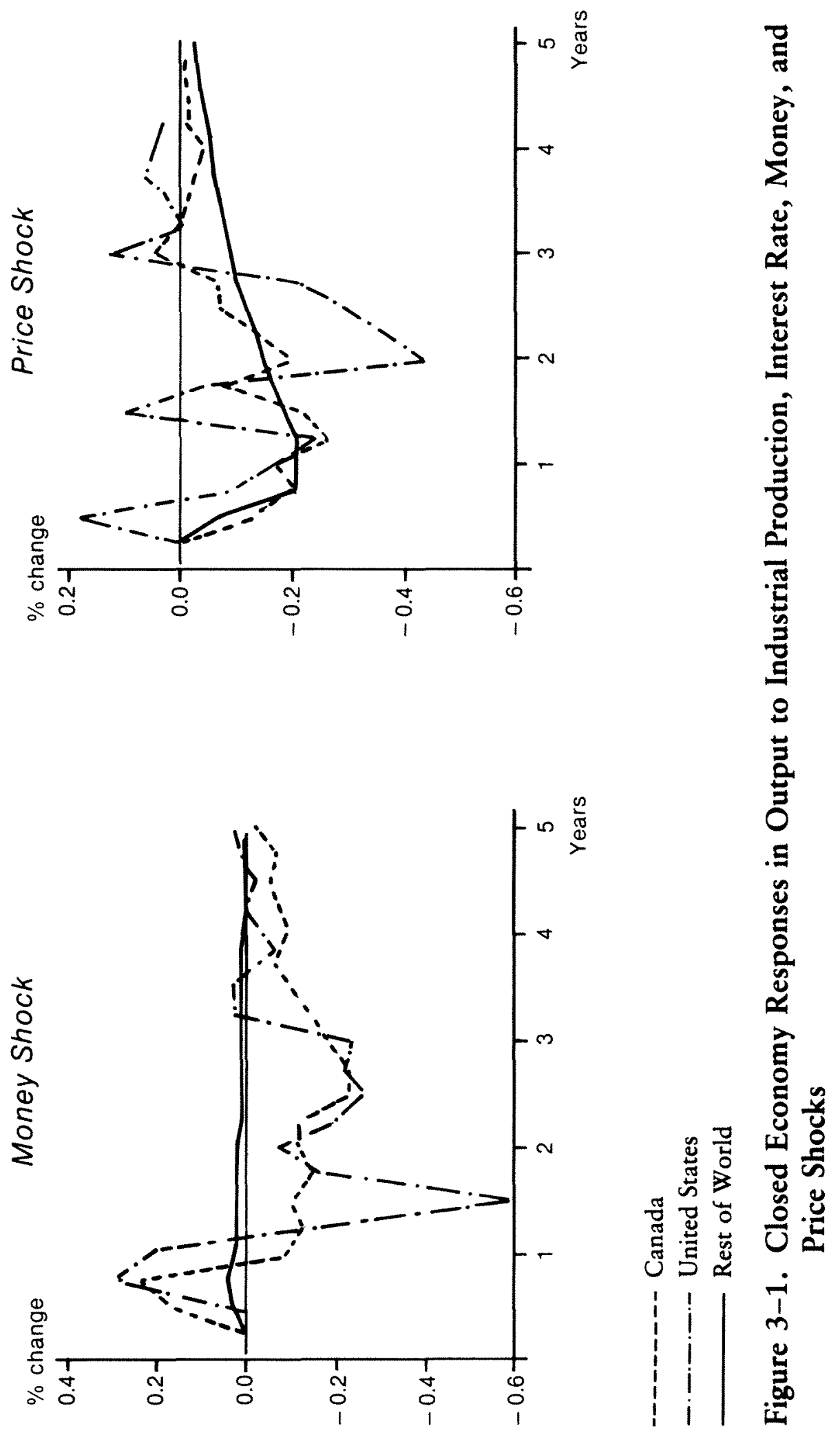
94 - How Open Is the U.S. Economy?
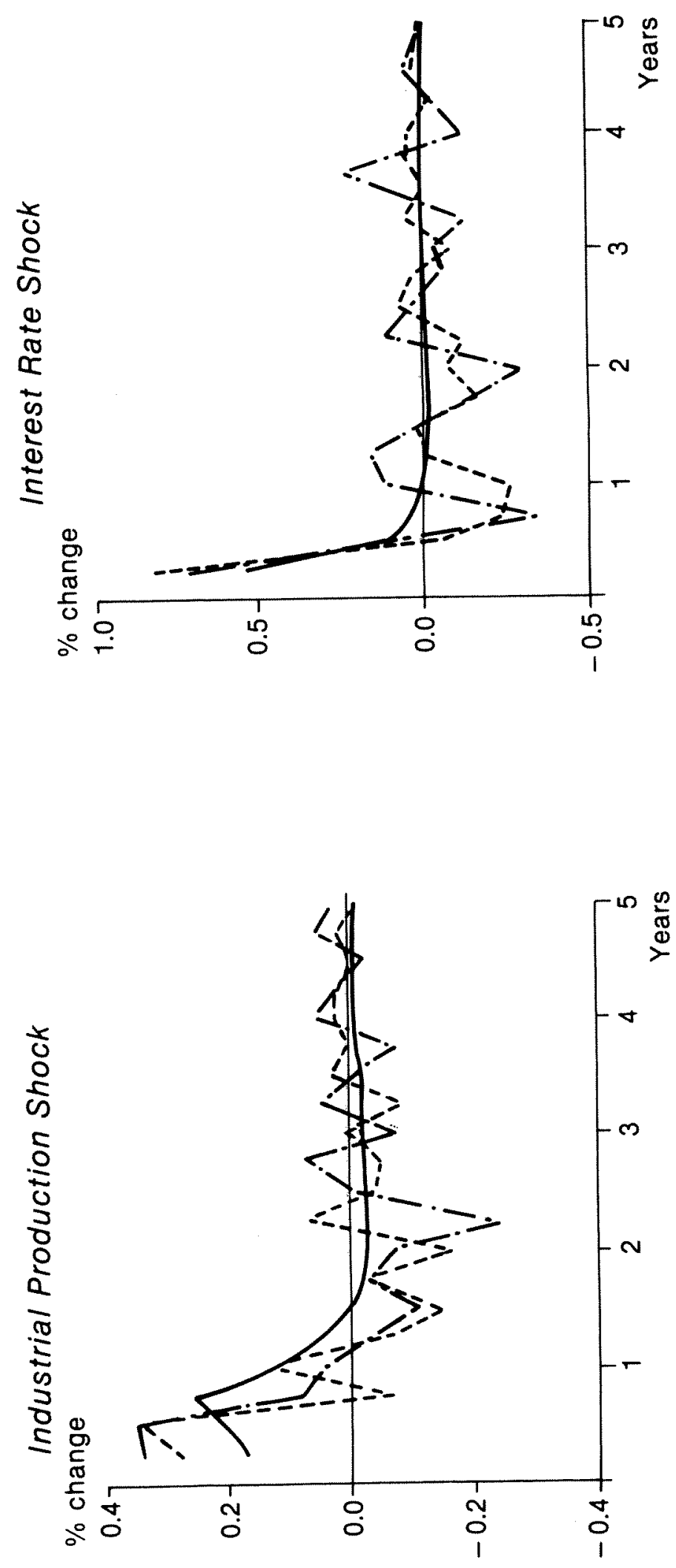


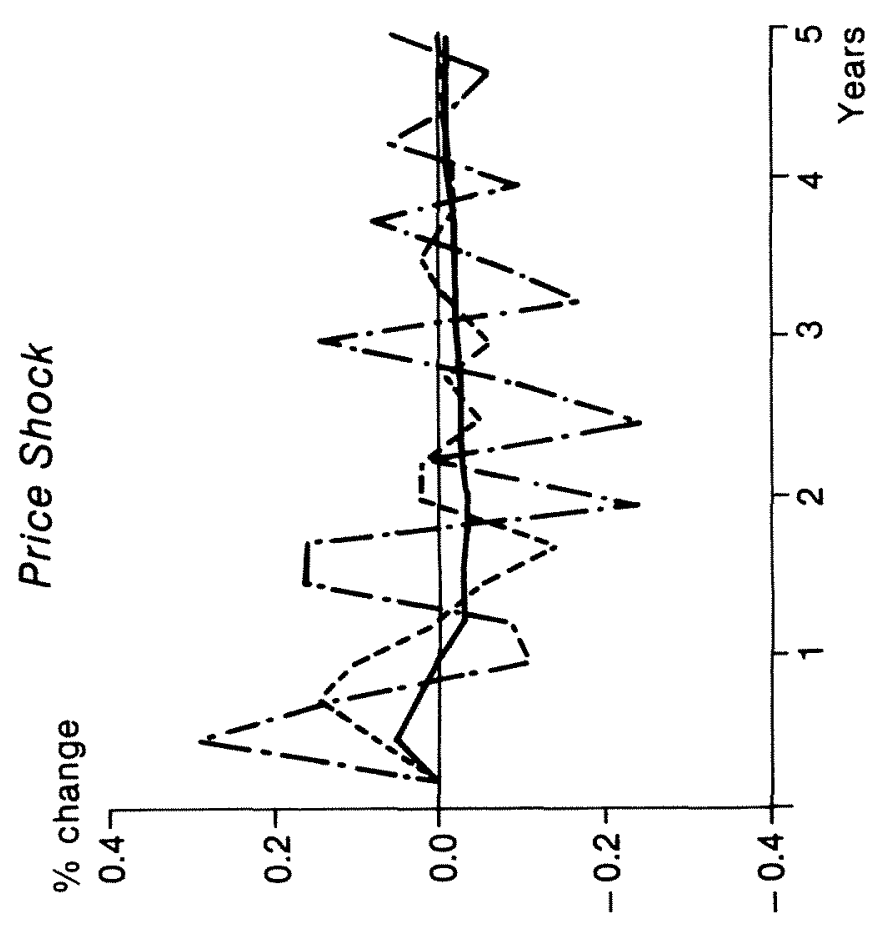

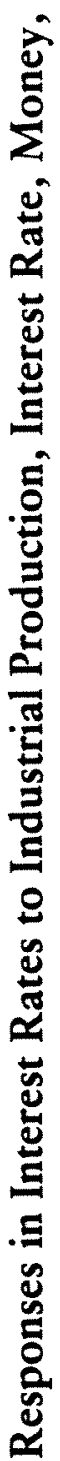
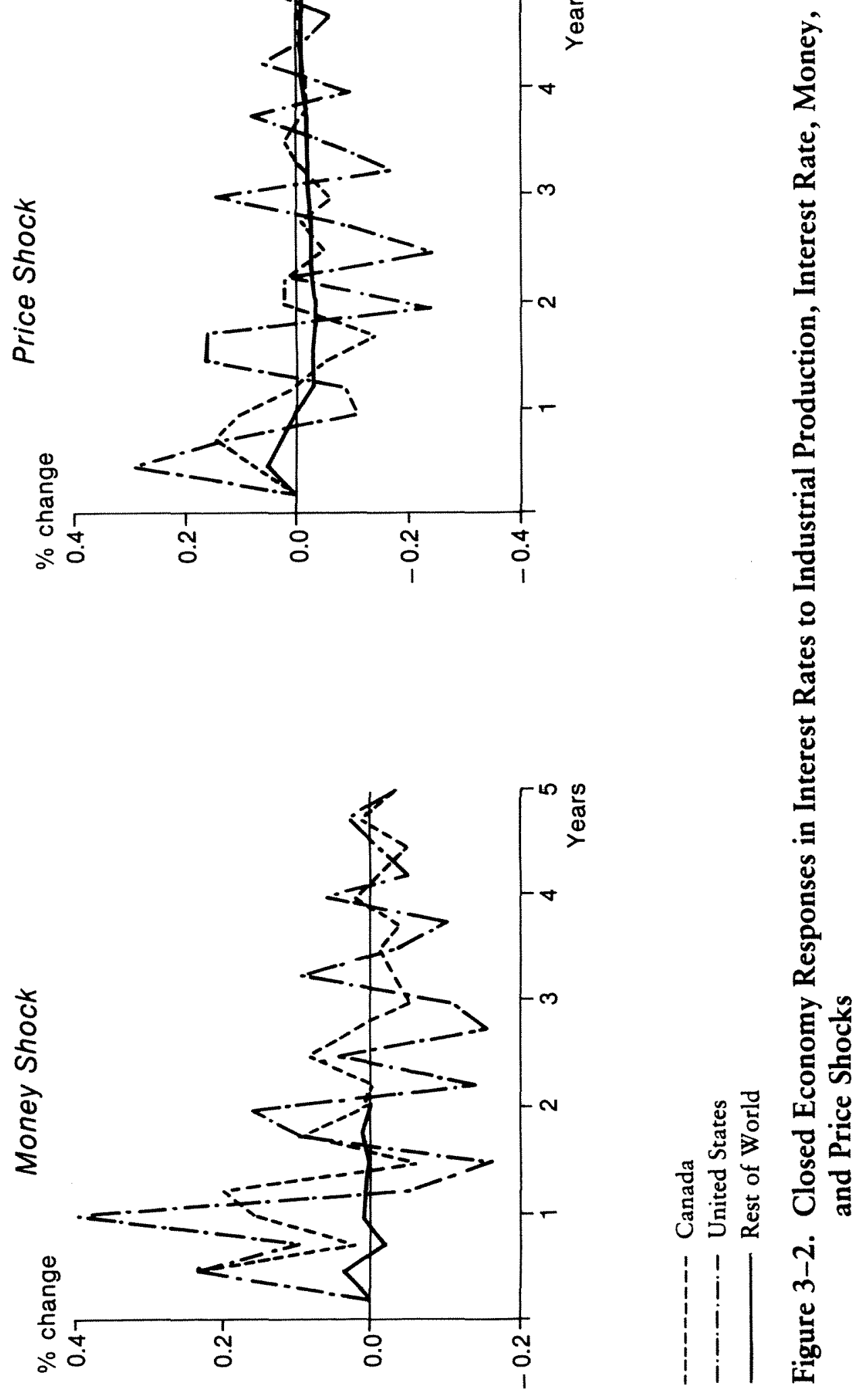


\section{How Open Is the U.S. Economy?}
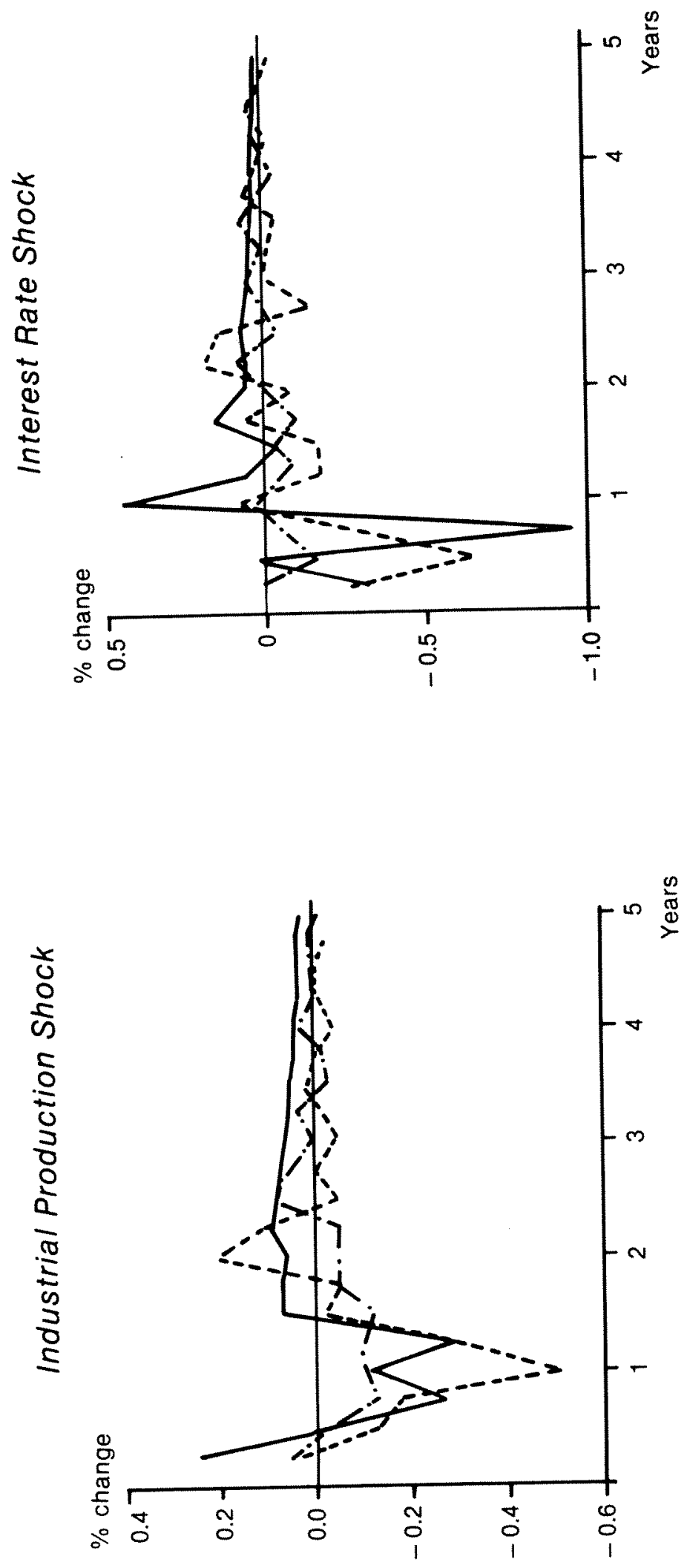

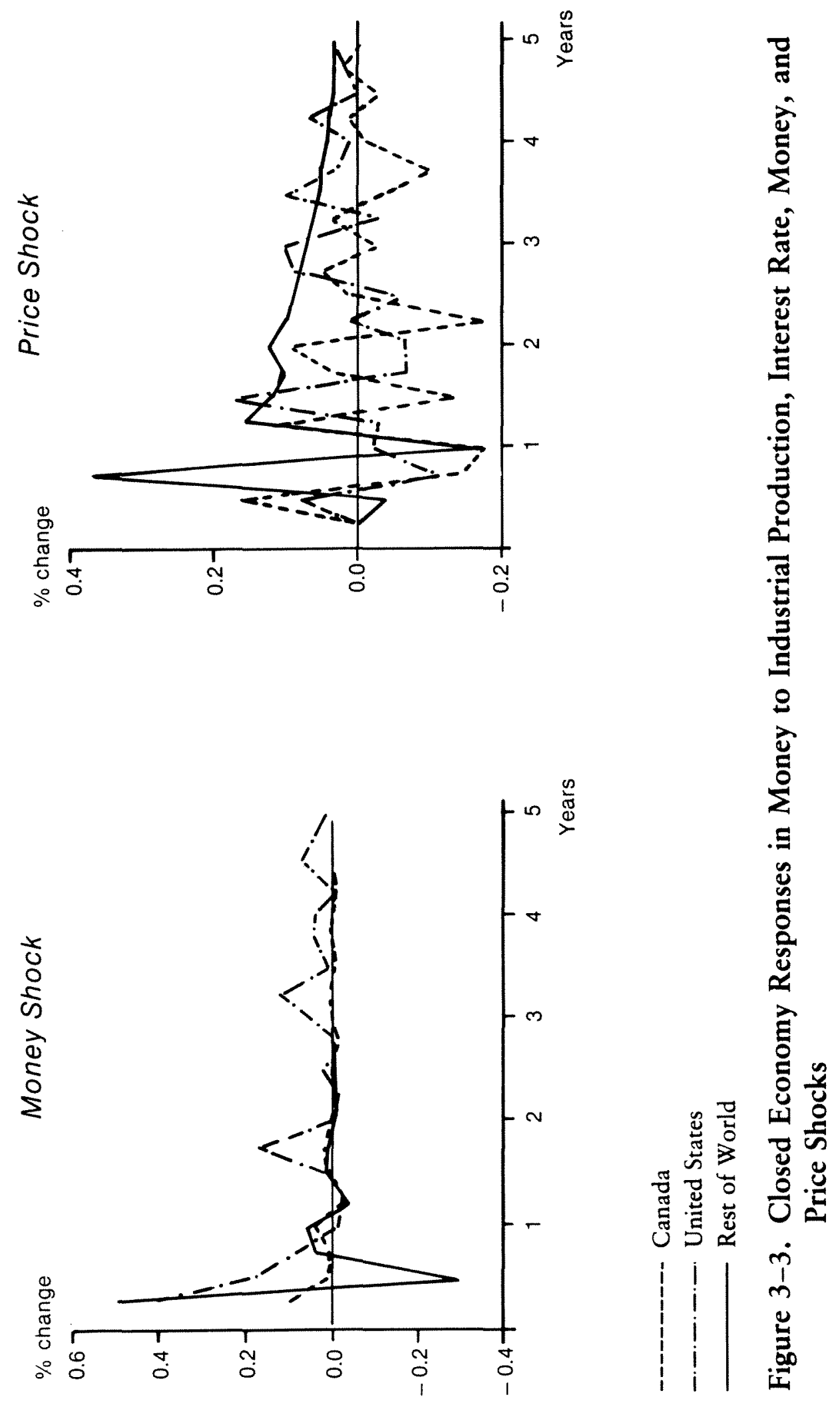

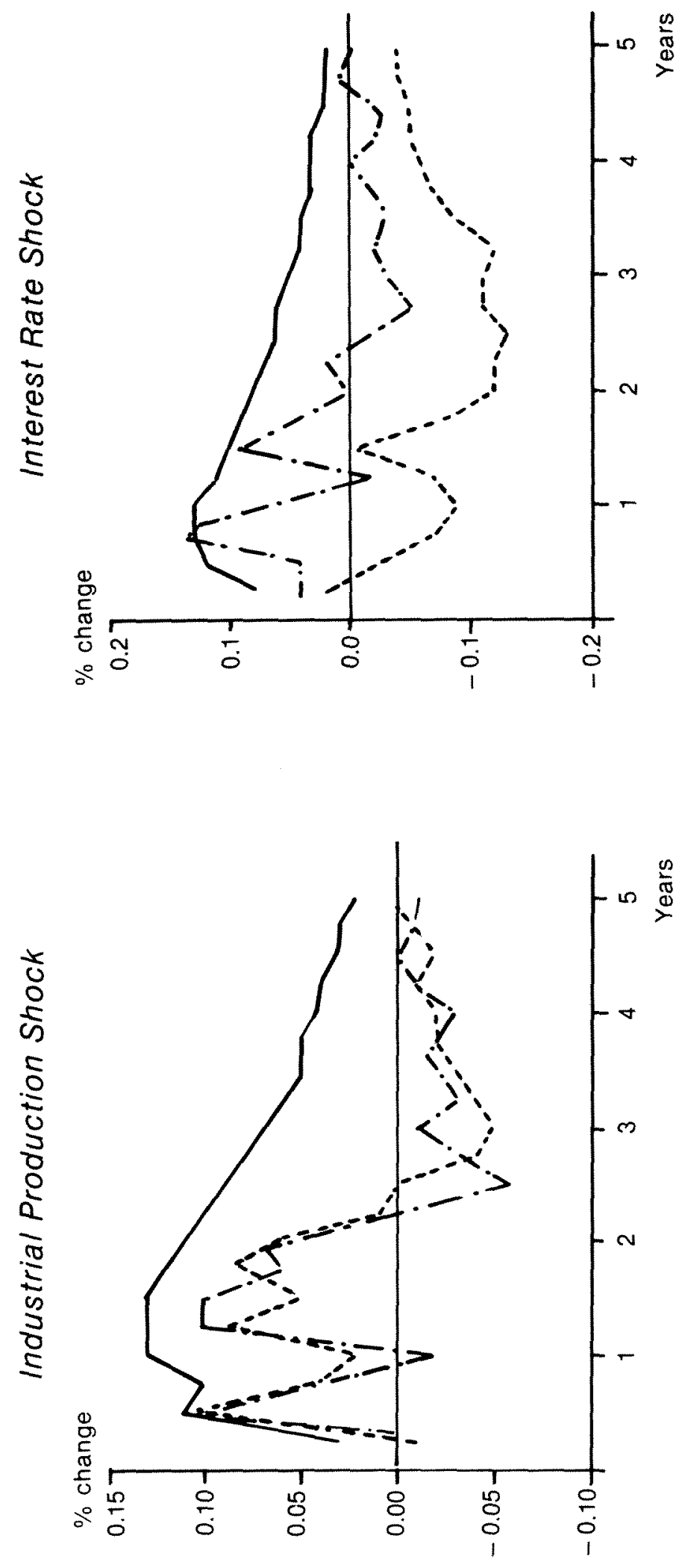


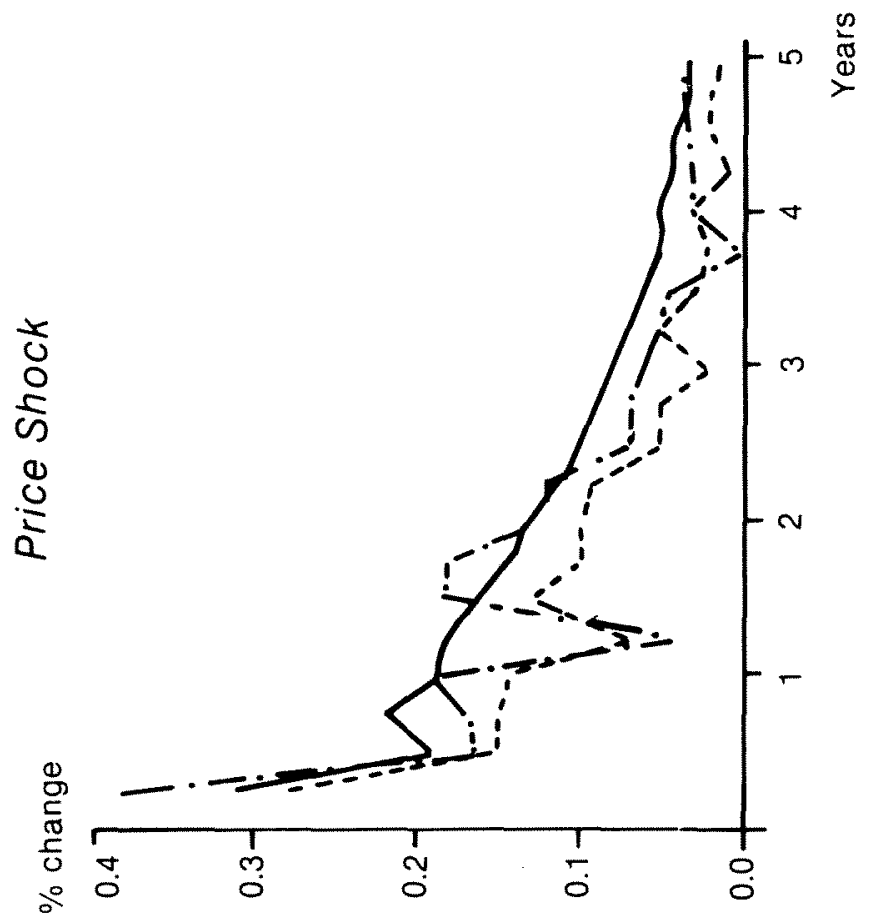

jo

氖

岕

ํㅗㄹ
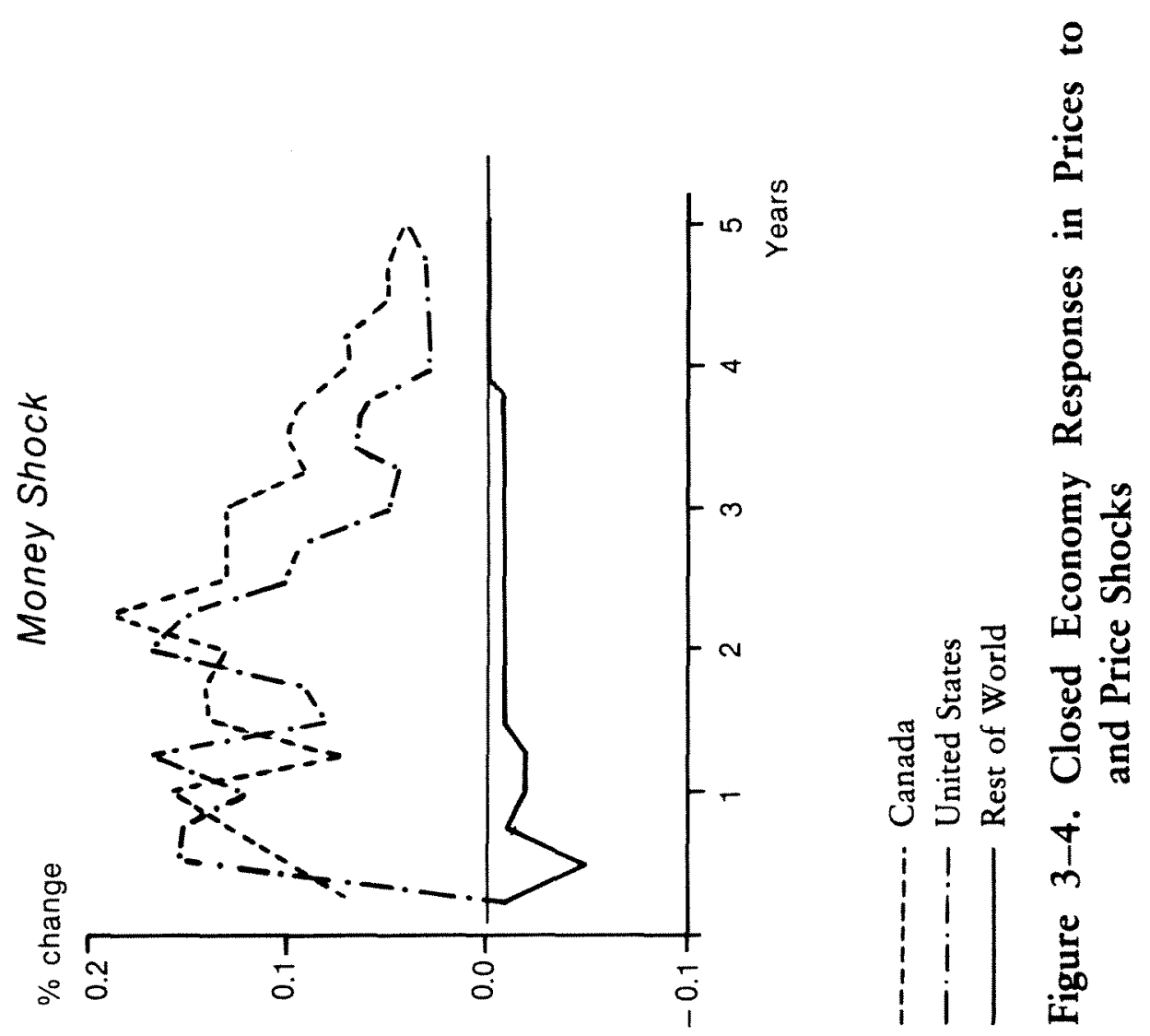
Table 3-9

Testing the Lag Structures of Open Economy Models, 1962.1-1984.4

Canada (United States) ${ }^{\mathrm{a}}$

1962.3-1984.4

4 vs. 3 lags

$\chi^{2}(36)=63.6^{*}$

Reject 3

1970.3-1984.4

4 vs. 3 lags

$\chi^{2}(36)=41.9$

Accept 3

3 vs. 2 lags

$\chi^{2}(36)=42.9$

Accept 2

2 vs. 1 lags

$\chi^{2}(36)=64.2^{*}$

Reject 1

United States (Canada)

1962.1-1984.4

4 vs. 3 lags

$\chi^{2}(36)=76.9^{*}$

Reject 3

1970.3-1984.4

4 vs. 3 lags

$\chi^{2}(36)=44.2$

Accept 3

3 vs. 2 lags

$\chi^{2}(36)=33.4$

Accept 2

2 vs. 1 lags

$\chi^{2}(36)=39.6$

Accept 1

United States (Rest of World)

1965.1-1984.4

4 vs. 3 lags

$\chi^{2}(36)=88.4^{*}$

Reject 3

1973.1-1984.4

3 vs. 2 lags

$\chi^{2}(36)=33.2$

Accept 2

2 vs. 1 lags

$\chi^{2}(36)=30.8$

Accept 1

Rest of World (United States)

1965.1-1984.4

4 vs. 3 lags

$\chi^{2}(36)=37.6$

Accept 3

3 vs. 2 lags

$\chi^{2}(36)=33.2$

Accept 2

2 vs. 1 lags

$\chi^{2}(36)=58.6^{*}$

Reject 1

1973.1-1984.4

3 vs. 2 lags

$\chi^{2}(36)=21.92$

Reject 1

2 vs. 1 lags

$\chi^{2}(36)=45.71$

Accept 1

a Dependent variables for country $x$ are regressed on lagged variables from $x$ and $(y)$.

* Significant at the 5.0 percent level.

Parameter Estimates. The parameter estimates for the open economy models are reported in tables 3-10 through 3-13. Two sets of results are shown for Canada (tables 3-10 and 3-11): one for a full sample running from 1962.3 to 1984.4 , and the other for a shorter sample running from 1970.3 to 1984.4. The latter corresponds to the period of flexible exchange rates in 
Canada. Though similar models have been estimated for the United States and ROW, over the period 1973.1-1984.4, only those for Canada are reported below since the same general patterns and relationships are observed in all three models.

The coefficients on many of the domestic variables that were significant in the closed economy models have retained their signs and significance in the open economy models. Several foreign variables also play a significant role, however, and their presence has produced dramatic changes in some important domestic variables. In the case of Canada, lagged domestic interest rates $\left(R_{\mathrm{c}}\right)$ now enter the money equation with a positive and statistically insignificant coefficient. Most of their influence appears to have been usurped by $R_{\mathrm{us}}{ }^{20}$

There are other instances, however, in which the addition of foreign variables seems to have enhanced the importance of domestic variables. Notable examples include $M_{\mathrm{us}}$ in the U.S. output equation and $P_{\mathrm{w}}$ in the ROW money equation. It is difficult therefore to identify any consistent pattern among the domestic variables in the closed versus open economy models, though the results across countries are once again similar.

While performances of some of the foreign variables in the equations are rather mixed, foreign interest rates and exchange rates have a strong and statistically significant impact in all the open economy models that we have tested. An appreciation of the exchange rate in our Canadian and U.S. models (represented by higher values of $S_{\mathrm{c}-\mathrm{us}}$ and $S_{\mathrm{us}-\mathrm{w}}$ ) depresses domestic output, prices, and money growth (see tables 3-10 and 3-12). A strong Canadian dollar also lowers short-term interest rates in Canada, but it is not clear how this result should be interpreted. It could reflect expectations of lower inflation following a currency appreciation, or a tendency on the part of Canadian policymakers to lean against the wind and to resist exchange rate pressures with offsetting movements in $R_{\mathrm{c}}{ }^{21} \mathrm{~A}$ similar response is observed in the U.S. equation for $R_{\text {us }}$, but the coefficient on $S_{\mathrm{w} \text {-us }}$ is not statistically significant.

Higher foreign interest rates reduce money growth in Canada and the United States, and raise domestic interest rates. They also cause the home currencies in both countries to appreciate. Though this positive reaction is difficult to explain, it is consistent with other published work which has shown that future spot rates are systematically misforecast by movements in international interest rates and the forward premiums on foreign exchange. ${ }^{22}$

Foreign interest rates and exchange rates are less significant in the ROW model (see table 3-13), but the signs on their coefficients are usually the same as those in the Canadian and U.S. models. In any case, likelihood ratio tests indicate that the foreign variables taken as a group are significant in all three models. Therefore, none of the "countries" in this sample is adequately represented by a closed economy specification. 
Table 3-10

Parameter Estimates for the Open Economy Model of Canada, 1962.3-1984.4

\begin{tabular}{lcccccc} 
Equation & Constant & $A(L) U_{c}^{\mathrm{a}}$ & $B(L) P_{\mathrm{c}}^{\mathrm{a}}$ & $C(L) M_{\mathrm{c}}^{\mathrm{a}}$ & $D(L) R_{\mathrm{c}}^{\mathrm{a}}$ & $E(L) U_{\mathrm{us}}^{\mathrm{a}}$ \\
\hline$U_{\mathrm{c}}$ & 0.012 & -0.618 & -2.29 & 0.540 & 0.078 & 0.509 \\
& $(1.75)^{*}$ & $(0.81)$ & $(3.07)^{* *}$ & $(2.63)^{*}$ & $(0.74)$ & $(0.93)$ \\
$P_{\mathrm{c}}$ & -0.002 & 0.048 & 0.800 & 0.053 & 0.087 & 0.043 \\
& $(1.35)$ & $(1.24)$ & $(6.87)^{*}$ & $(1.43)$ & $(0.75)$ & $(2.00)^{*}$ \\
$M_{\mathrm{c}}$ & 0.005 & 0.014 & -0.815 & 0.596 & 0.567 & -0.169 \\
& $(0.72)$ & $(1.84)$ & $(1.74)$ & $(3.18)^{*}$ & $(0.99)$ & $(1.84)$ \\
$R_{\mathrm{c}}$ & 0.004 & 0.375 & -0.155 & 0.238 & -0.249 & -0.154 \\
& $(1.96)^{*}$ & $(0.96)$ & $(1.61)$ & $(2.89)^{*}$ & $(0.63)$ & $(0.50)$ \\
$S_{\mathrm{c}-\text { us }}$ & 0.014 & -0.018 & 0.012 & 0.328 & 0.311 & -0.717 \\
& $(2.90)^{*}$ & $(1.41)$ & $(0.46)$ & $(2.22)^{*}$ & $(0.63)$ & $(3.42)^{*}$ \\
\hline
\end{tabular}

${ }^{a}$ Sum of lagged coefficients where lag operators are of order 4. F-statistic testing joint significance of all lagged coefficients reported in parentheses.

b Box-Pierce Q-statistic.

* Significant at the 10.0 percent level.

* * Significant at the 5.0 percent level.

Table 3-11

Parameter Estimates for the Open Economy Model of Canada, 1970.3-1984.4

\begin{tabular}{lcccccc} 
Equation & Constant & $A(L) U_{\mathrm{c}}{ }^{\mathrm{a}}$ & $B(L) \mathrm{P}_{\mathrm{c}}^{\mathrm{a}}$ & $C(L) M_{\mathrm{c}}{ }^{\mathrm{a}}$ & $D(L) R_{\mathrm{c}}{ }^{\mathrm{a}}$ & $E(L) U_{\mathrm{us}}{ }^{\mathrm{a}}$ \\
\hline$U_{\mathrm{c}}$ & -0.003 & -0.298 & -1.497 & 0.767 & 0.654 & 0.313 \\
& $(0.23)$ & $(0.74)$ & $(3.76)^{* *}$ & $(8.45)^{* *}$ & $(1.08)$ & $(1.68)$ \\
$P_{\mathrm{c}}$ & 0.001 & 0.209 & 0.860 & -0.020 & -0.863 & -0.136 \\
& $(1.31)$ & $(6.57)^{* *}$ & $(21.62)^{*}$ & $(2.10)$ & $(0.30)$ & $(4.67)^{*}$ \\
$M_{\mathrm{c}}$ & 0.015 & 0.079 & -0.636 & 0.515 & 0.204 & -0.303 \\
& $(1.55)$ & $(1.45)$ & $(12.58)^{* *}$ & $(5.47)^{* *}$ & $\{0.29)$ & $(5.33)^{* *}$ \\
$R_{\mathrm{c}}$ & -0.014 & 0.317 & 0.250 & 0.198 & -0.005 & -0.119 \\
& $(1.93)^{* *}$ & $(2.85)^{*}$ & $(0.78)$ & $(1.92)^{* *}$ & $(0.42)$ & $(0.48)$ \\
$S_{\mathrm{c}-\text { us }}$ & 0.007 & -0.146 & 0.054 & 0.204 & -0.219 & -0.067 \\
& $(0.65)$ & $(0.18)$ & $(0.04)$ & $(0.96)$ & $(1.41)$ & $(0.07)$ \\
\hline
\end{tabular}

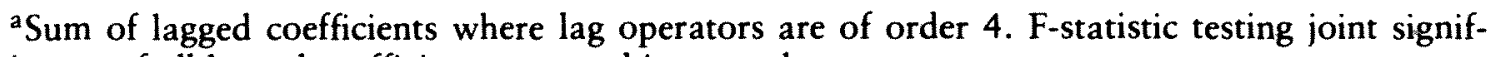
icance of all lagged coefficients reported in parentheses.

${ }^{b}$ Box-Pierce Q-statistic.

"Significant at the 10.0 percent level.

* *Significant at the 5.0 percent level. 


\begin{tabular}{|c|c|c|c|c|c|c|c|}
\hline$F(L) P_{u s}{ }^{a}$ & $G(L) M_{\mathrm{us}}^{\mathrm{a}}$ & $H(L) R_{\mathrm{us}^{\mathrm{a}}}$ & $I(L) S_{\mathrm{c}-\mathrm{us}} \mathrm{a}^{\mathrm{a}}$ & $\bar{R}^{2}$ & $\begin{array}{l}\text { Durbin- } \\
\text { Watson } \\
\text { Statistic }\end{array}$ & $\begin{array}{c}\text { Standard } \\
\text { Error }\end{array}$ & $Q(27)^{\mathrm{b}}$ \\
\hline $\begin{array}{c}0.768 \\
(1.27)\end{array}$ & $\begin{array}{c}0.793 \\
(1.63)\end{array}$ & $\begin{array}{c}-0.798 \\
(0.73)\end{array}$ & $\begin{array}{c}-0.440 \\
(2.00)^{*}\end{array}$ & 0.446 & 1.85 & 0.014 & 22.10 \\
\hline $\begin{array}{c}0.225 \\
(1.01)\end{array}$ & $\begin{array}{c}0.039 \\
(0.76)\end{array}$ & $\begin{array}{c}0.065 \\
(0.98)\end{array}$ & $\begin{array}{c}-0.071 \\
(2.09)^{*}\end{array}$ & 0.834 & 2.13 & 0.003 & 17.13 \\
\hline $\begin{array}{c}0.474 \\
(1.08)\end{array}$ & $\begin{array}{c}0.713 \\
(1.19)\end{array}$ & $\begin{array}{l}-1.587 \\
(2.76)^{*}\end{array}$ & $\begin{array}{c}-0.165 \\
0.84\end{array}$ & 0.394 & 1.95 & 0.014 & 24.58 \\
\hline $\begin{array}{c}0.557 \\
(2.20)^{*}\end{array}$ & $\begin{array}{c}-0.343 \\
(3.30)^{*}\end{array}$ & $\begin{array}{c}0.429 \\
(10.31)^{* *}\end{array}$ & $\begin{array}{l}-0.303 \\
(2.93)^{* *}\end{array}$ & 0.613 & 1.80 & 0.007 & 9.17 \\
\hline $\begin{array}{c}-1.150 \\
(2.43)^{*}\end{array}$ & $\begin{array}{c}-0.036 \\
(0.75)\end{array}$ & $\begin{array}{l}1.147 \\
(3.87)^{*}\end{array}$ & $\begin{array}{c}0.320 \\
(1.50)\end{array}$ & 0.412 & 1.93 & 0.010 & 22.12 \\
\hline
\end{tabular}

\begin{tabular}{|c|c|c|c|c|c|c|c|}
\hline$F(L) P_{\mathrm{us}}^{\mathrm{a}}$ & $G(L) M_{\mathrm{us}^{\mathrm{a}}}$ & $H(L) R_{\mathrm{us}^{\mathrm{a}}}^{\mathrm{a}}$ & $I(L) S_{\mathrm{c}-\mathrm{us}}{ }^{\mathrm{a}}$ & $\bar{R}^{2}$ & $\begin{array}{l}\text { Durbin- } \\
\text { Watson } \\
\text { Statistic }\end{array}$ & $\begin{array}{c}\text { Standard } \\
\text { Error }\end{array}$ & $Q(27)^{b}$ \\
\hline $\begin{array}{c}0.149 \\
(0.06)\end{array}$ & $\begin{array}{c}1.195 \\
(2.52)^{*}\end{array}$ & $\begin{array}{c}-0.509 \\
(1.03)\end{array}$ & $\begin{array}{c}-0.076 \\
(0.42)\end{array}$ & 0.457 & 1.91 & 0.016 & 22.49 \\
\hline $\begin{array}{c}0.202 \\
(1.89)\end{array}$ & $\begin{array}{c}-0.108 \\
(0.28)\end{array}$ & $\begin{array}{r}0.023 \\
(0.08)\end{array}$ & $\begin{array}{r}-0.031 \\
(1.86)\end{array}$ & 0.758 & 2.04 & 0.004 & 1.93 \\
\hline $\begin{array}{r}0.109 \\
(0.66)\end{array}$ & $\begin{array}{c}0.382 \\
(2.67)^{*}\end{array}$ & $\begin{array}{c}-0.648 \\
(3.36)^{*}\end{array}$ & $\begin{array}{l}-.082 \\
(1.18)\end{array}$ & 0.536 & 2.07 & 0.013 & 24.38 \\
\hline $\begin{array}{c}0.381 \\
(0.87)\end{array}$ & $\begin{array}{c}-0.163 \\
(0.99)\end{array}$ & $\begin{array}{c}0.264 \\
(4.87)^{*}\end{array}$ & $\begin{array}{c}-0.094 \\
(0.68)\end{array}$ & 0.503 & 1.81 & 0.010 & 11.65 \\
\hline $\begin{array}{c}-0.541 \\
(0.74)\end{array}$ & $\begin{array}{c}-0.241 \\
(0.49)\end{array}$ & $\begin{array}{c}0.265 \\
(0.81)\end{array}$ & $\begin{array}{c}0.459 \\
(5.85)^{*}\end{array}$ & 0.125 & 2.11 & 0.014 & 9.62 \\
\hline
\end{tabular}


Table 3-12

Parameter Estimates for the Open Economy Model of United States, 1965.1-1984.4

\begin{tabular}{lcccccc} 
Equation & Constant & $A(L) U_{\mathrm{us}}{ }^{\mathrm{a}}$ & $B(L) \mathrm{P}_{\mathrm{us}}{ }^{\mathrm{a}}$ & $C(L) M_{\mathrm{us}}{ }^{\mathrm{a}}$ & $D(L) R_{\mathrm{us}}{ }^{\mathrm{a}}$ & $E(L) U_{\mathrm{w}}{ }^{\mathrm{a}}$ \\
\hline$U_{\mathrm{us}}$ & -0.001 & 0.682 & 0.927 & 1.112 & -1.601 & -0.238 \\
& $(0.02)$ & $(1.89)$ & $(1.22)$ & $(2.49)^{*}$ & $(3.36)^{* *}$ & $(2.29)^{*}$ \\
$\mathrm{P}_{\mathrm{us}}$ & -0.006 & -0.028 & 0.544 & 0.286 & 0.056 & 0.061 \\
& $(2.99)^{* *}$ & $(3.60)^{*}$ & $(3.61)^{* *}$ & $(5.00)^{* *}$ & $(0.19)$ & $(0.49)$ \\
$M_{\mathrm{us}}$ & 0.002 & 0.121 & 0.258 & 0.798 & -0.767 & 0.014 \\
& $(0.57)$ & $(0.60)$ & $(1.34)$ & $(5.89)^{* *}$ & $(6.87)^{* *}$ & $(0.89)$ \\
$R_{\mathrm{us}}$ & -0.018 & 0.801 & 1.379 & 0.507 & -1.424 & -0.330 \\
& $(2.62)^{* *}$ & $(5.01)^{* *}$ & $(1.41)$ & $(8.80)^{* *}$ & $(5.48)$ & $(1.09)^{*}$ \\
$S_{\mathrm{w}-\mathrm{us}}$ & 0.004 & 0.395 & 0.687 & 0.417 & -1.354 & -0.685 \\
& $(0.26)$ & $(0.57)$ & $(1.68)$ & $(1.18)$ & $(2.62)^{* *}$ & $(1.20)$
\end{tabular}

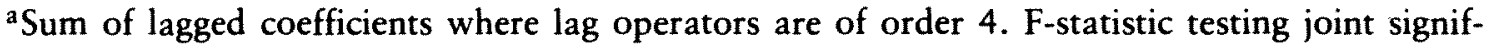
icance of all lagged coefficients reported in parentheses.

b Box-Pierce Q-statistic.

* Significant at the 10.0 percent level.

* * Significant at the 5.0 percent level.

Table 3-13

Parameter Estimates for the Open Economy Model of Rest of World, 1965.1-1984.4

\begin{tabular}{lcccccc} 
Equation & Constant & $A(L) U_{\mathrm{w}}{ }^{\mathrm{a}}$ & $B(L) P_{\mathrm{w}}{ }^{\mathrm{a}}$ & $C(L) M_{\mathrm{w}}{ }^{\mathrm{a}}$ & $D(L) R_{\mathrm{w}}{ }^{\mathrm{a}}$ & $E(L) U_{\mathrm{us}}{ }^{\mathrm{a}}$ \\
\hline$U_{\mathrm{w}}$ & 0.011 & 0.116 & -0.487 & 0.005 & 0.405 & 0.271 \\
& $(1.82)^{* *}$ & $(1.62)$ & $(0.89)$ & $(0.03)$ & $(0.81)$ & $(2.48)^{*}$ \\
$P_{\mathrm{w}}$ & -0.005 & 0.473 & 1.013 & -0.018 & 0.150 & -0.028 \\
& $(0.30)$ & $(2.54)^{*}$ & $(51.60)^{* *}$ & $(0.80)$ & $(1.06)$ & $(0.76)^{*}$ \\
$M_{\mathrm{w}}$ & 0.043 & -0.151 & 4.408 & -1.259 & -2.822 & -0.271 \\
& $(1.78)^{* *}$ & $(0.163)$ & $(4.32)^{* *}$ & $(22.05)^{* *}$ & $(2.32)^{*}$ & $(1.31)$ \\
$R_{\mathrm{w}}$ & -0.004 & 0.216 & 0.036 & 0.008 & 0.023 & -0.050 \\
& $(1.50)$ & $(3.70)^{* *}$ & $(0.19)$ & $(0.32)$ & $(0.23)$ & $(0.77)$ \\
$S_{\mathrm{w}-\mathrm{us}}$ & 0.005 & 0.126 & -0.195 & 0.074 & -1.091 & -0.216 \\
& $(0.39)$ & $(0.40)$ & $(0.04)$ & $(2.34)^{*}$ & $(2.66)^{*}$ & $(1.90)$ \\
\hline
\end{tabular}

aSum of lagged coefficients where lag operators are of order 2. F-statistic testing joint significance of all lagged coefficients reported in parentheses.

${ }^{b}$ Box-Pierce Q-statistic.

* Significant at the 10.0 percent level.

* * Significant at the 5.0 percent level. 


\begin{tabular}{|c|c|c|c|c|c|c|c|}
\hline$F(L) P_{\mathrm{w}}{ }^{\mathrm{a}}$ & $G(L) M_{w}{ }^{a}$ & $H(L) R_{\mathrm{w}}{ }^{\mathrm{a}}$ & $I(L) S_{\mathrm{us}-\mathrm{w}}{ }^{\mathrm{a}}$ & $\bar{R}^{2}$ & $\begin{array}{l}\text { Durbin- } \\
\text { Watson } \\
\text { Statistic }\end{array}$ & $\begin{array}{c}\text { Standard } \\
\text { Error }\end{array}$ & $Q(27)^{b}$ \\
\hline $\begin{array}{c}0.188 \\
(0.94)\end{array}$ & $\begin{array}{c}-0.008 \\
(1.06)\end{array}$ & $\begin{array}{c}1.444 \\
(1.15)\end{array}$ & $\begin{array}{c}-0.438 \\
(3.60)^{*}\end{array}$ & 0.589 & 2.05 & 0.015 & 15.88 \\
\hline $\begin{array}{c}0.138 \\
(0.38)\end{array}$ & $\begin{array}{c}0.234 \\
(10.46)^{*}\end{array}$ & $\begin{array}{c}0.669 \\
(3.32)^{*}\end{array}$ & $\begin{array}{c}-0.023 \\
(2.43)^{\star}\end{array}$ & 0.846 & 1.57 & 0.003 & 14.81 \\
\hline $\begin{array}{c}0.204 \\
(0.82)\end{array}$ & $\begin{array}{r}0.011 \\
(1.30)\end{array}$ & $\begin{array}{c}-0.481 \\
(1.14)\end{array}$ & $\begin{array}{c}-0.087 \\
(2.32)^{*}\end{array}$ & 0.358 & 1.99 & 0.006 & 19.06 \\
\hline $\begin{array}{c}-1.125 \\
(2.90)^{*}\end{array}$ & $\begin{array}{c}0.269 \\
(1.48)\end{array}$ & $\begin{array}{c}2.170 \\
(3.03)^{*}\end{array}$ & $\begin{array}{r}-0.139 \\
(0.96)\end{array}$ & 0.524 & 1.82 & 0.010 & 16.80 \\
\hline $\begin{array}{c}-0.885 \\
(0.61)\end{array}$ & $\begin{array}{c}-0.060 \\
(1.27)\end{array}$ & $\begin{array}{c}3.293 \\
(2.38)^{*}\end{array}$ & $\begin{array}{c}0.444 \\
(2.87)^{* *}\end{array}$ & 0.254 & 2.17 & 0.025 & 22.79 \\
\hline
\end{tabular}

\begin{tabular}{cccccccc}
\hline$F(L) P_{\mathrm{us}}{ }^{\mathrm{a}}$ & $G(L) M_{\mathrm{us}}{ }^{\mathrm{a}}$ & $H(L) R_{\mathrm{us}}{ }^{\mathrm{a}}$ & $I(L) S_{\mathrm{us}-\mathrm{w}}{ }^{\mathrm{a}}$ & $\bar{R}^{2}$ & $\begin{array}{c}\text { Durbin- } \\
\text { Watson } \\
\text { Statistic }\end{array}$ & $\begin{array}{c}\text { Standard } \\
\text { Error }\end{array}$ & $Q(27)^{\mathrm{b}}$ \\
\hline-0.192 & 0.331 & -0.215 & -0.012 & 0.356 & 1.93 & 0.012 & 8.72 \\
$(0.21)$ & $(1.99)$ & $(0.52)$ & $(0.52)$ & & & & \\
-0.128 & 0.123 & 0.042 & -0.037 & 0.828 & 2.16 & 0.003 & 34.87 \\
$(1.31)$ & $(1.22)$ & $(0.68)$ & $(6.43)^{* *}$ & & & & \\
-3.86 & -0.651 & 1.020 & -0.357 & 0.290 & 2.12 & 0.050 & 11.10 \\
$(2.81)^{*}$ & $(0.71)$ & $(0.53)$ & $(1.03)$ & & & & \\
0.074 & 0.065 & 0.340 & -0.011 & 0.447 & 1.91 & 0.005 & 17.78 \\
$(0.59)$ & $(1.93)$ & $(9.61)^{* *}$ & $(0.72)$ & & & & \\
0.279 & -0.309 & 0.936 & 0.432 & 0.141 & 1.94 & 0.003 & 12.13 \\
$(2.35)^{*}$ & $(0.12)$ & $(1.61)$ & $(6.27)^{* *}$ & & & & \\
\hline \multicolumn{7}{c}{}
\end{tabular}


The previous discussion was based on regression results that were obtained from models estimated over the full sample period, spanning both fixed and flexible exchange rate regimes. As noted earlier, however, the models have also been estimated over shorter samples corresponding to the most recent period of flexible exchange rates. The Canadian estimates for the shorter sample are reported in table 3-11. As the reader can see, the results are not noticeably different from those reported in table 3-10 for the full sample, suggesting that the major macro relationships linking the U.S. and Canadian economies have remained relatively stable throughout the 1962-84 period. Some differences can be observed in the price and exchange rate equations, but tests for structural stability cannot reject the hypothesis of no significant change between the fixed and flexible exchange rate periods. While this result was not expected, identical results were obtained for the open economy models of the United States and ROW (see table 3-14). ${ }^{23}$

As a further check on the reliability of our regression results, a number of

Table 3-14

Testing the Parameter Stability of Closed and Open Economy Models, 1962.1-1984.4

Closed economy

Canada:

$1962.3-1970.2$ vs. $1970.3-1984.4$

3 lags $^{\mathbf{a}}$

$\chi^{2}(52)=70.1^{*} \quad$ Reject stability

United States:

1962.1-1972.4 vs. 1973.1-1984.4

6 lags

$\chi^{2}(100)=74.4 \quad$ Accept stability

Rest of World:

1964.1-1972.4 vs. $1973.1-1984.4$

2 lags

$$
\chi^{2}(36)=25.5 \quad \text { Accept stability }
$$

Open economy

Canada/United States:

1962.3-1970.2 vs. $1970.3-1984.4$

2 lags

$$
\chi^{2}(76)=70.8 \quad \text { Accept stability }
$$

United States/Rest of World:

1964.1-1972.2 vs. 1973.1-1984.4

$1 \mathrm{lag}$

$\chi^{2}(40)=41.8 \quad$ Accept stability

Rest of World/United States

1964.1-1972.2 vs. 1973.1-1984.4

$1 \mathrm{lag}$

$\chi^{2}(40)=34.2$

Accept stability

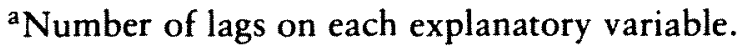

*Significant at the 5.0 percent level. 
Table 3-15

Granger-Causality Tests, 1962.3-1984.4

\begin{tabular}{|c|c|c|}
\hline \multicolumn{3}{|l|}{ United States $\rightarrow$ Canada $a^{\mathbf{a}}$} \\
\hline $1962.3-1984.4$ (4 lags) $)^{b}$ & $\chi^{2}(80)=124.7^{*}$ & Reject zero restrictions \\
\hline 1970.3-1984.4 (2 lags) & $\chi^{2}(40)=68.7^{*}$ & Reject zero restrictions \\
\hline \multicolumn{3}{|l|}{ Canada $\rightarrow$ United States } \\
\hline 1962.3-1984.4 (4 lags) & $\chi^{2}(80)=95.5$ & Accept zero restrictions \\
\hline 1970.3-1984.4 (2 lags) & $\chi^{2}(40)=41.0$ & Accept zero restrictions \\
\hline \multicolumn{3}{|c|}{ United States $\rightarrow$ Rest of World } \\
\hline 1965.1-1984.4 (2 lags) & $\chi^{2}(40)=69.3^{*}$ & Reject zero restrictions \\
\hline 1973.1-1984.4 (2 lags) & $\chi^{2}(40)=52.9^{* *}$ & Reject zero restrictions \\
\hline \multicolumn{3}{|c|}{ Rest of World - United States } \\
\hline 1965.1-1984.4 (4 lags) & $\chi^{2}(80)=122.0^{*}$ & Reject zero restrictions \\
\hline 1973.1-1984.4 (2 lags) & $\chi^{2}(40)=35.7$ & Accept zero restrictions \\
\hline
\end{tabular}

Granger-causality tests were run. The first two results, which are reported in table 3-15, can be regarded as a kind of acid test of the VAR methodology, at least as it applies to the present chapter. Canadian variables were added to a closed economy model of the United States, and U.S. variables were added to a closed economy model of Canada, in order to test the exogeneity of the domestic variables in each economy. The test results indicate that U.S. variables are highly significant in the Canadian model (the zero restrictions on the U.S. variables are strongly rejected), but that Canadian variables are not significant in the U.S. model. In terms of our earlier discussion in the section $\Delta \alpha \tau \alpha \ell$ Canada's relationship with the United States might be characterized as one of dependence as opposed to interdependence. (The terms dependence and interdependence are only used as a convenient means of classifying the causal relationships in table 3-15. They are not meant to imply anything about the political or economic sovereignty of the countries in question.) Though these results are not very surprising, strong evidence of bidirectional causality running between the two countries, or "unidirectional" causality running from Canada to the United States, would have clearly weakened the credibility of the present analysis. ${ }^{24}$

Similar tests on the U.S. and ROW models found evidence of bidirectional causality in the full sample, and unidirectional causality running from the United States to the rest of the world in the shorter sample-results that are also consistent with our priors. Because earlier tests could not reject 
structural stability over the fixed and flexible exchange rate periods, we will concentrate on the full sample results in the following discussion and assume bidirectional causality between these two countries.

Variance Decomposition and Impulse Responses. The calculation of variance decompositions for open economy models is complicated by the fact that consideration must be given to the order of the variables both within and across countries. In the case of Canada and the United States, the order of the variables across countries does not pose a problem since it is clear that U.S. variables should be given priority. The situation is more ambiguous in the case of the United States and ROW, however. In order to minimize any biases that might be introduced by inadvertently entering the variables in the wrong order, two sets of variance decompositions are calculated, giving the variables in each country an opportunity to go first.

Table 3-16 presents the residual correlations for Canada, the United States, and ROW. Since the highest value that is recorded is 0.51 , the variance decompositions are not expected to be very sensitive to changes in the order of the variables.

According the the figures reported in table $3-17$, over 50 percent of the forecast variance in Canadian output, prices, interest rates, and money can be attributed to innovations in foreign variables. Indeed, for variables $R_{\mathrm{c}}$ and $P_{c}$, the U.S. proportions exceed 60 percent. Greater independence is observed in the flexible exchange rate period (table 3-18), but the differences are not as large as one might have expected, especially for nominal variables such as $P_{\mathrm{c}}$ and $M_{\mathrm{c}}$.

It is well known that flexible exchange rates will not insulate economies from real external shocks. The primary attraction of flexible exchange rates is the independence that they presumably give policymakers with regard to controlling inflation. This claim would seem to be contradicted by the large proportion of $M_{\mathrm{c}}$ variance that is explained by U.S. output and interest rates. The importance of these U.S. variables in the Canadian money equation could have been caused by (1) currency substitution, ${ }^{25}(2)$ exchange rate targeting by Canada's central bank, ${ }^{26}$ or (3) an alternative called "goal and policy interdependence," which is more sympathetic to policymakers. ${ }^{27}$ While there is some evidence suggesting currency substitution is statistically significant in Canadian money demand equations, it is not generally regarded as economically important. The other explanations focusing on the objectives and reactions of Canadian policymakers represent more plausible alternatives. Discussion of these issues appears in the next section.

Foreign variables also have a significant influence in the variance decompositions of the United States and ROW (see tables 3-19 and 3-20), but the proportion of forecast variance explained by domestic shocks is generally much higher than in Canada. ${ }^{28}$ 


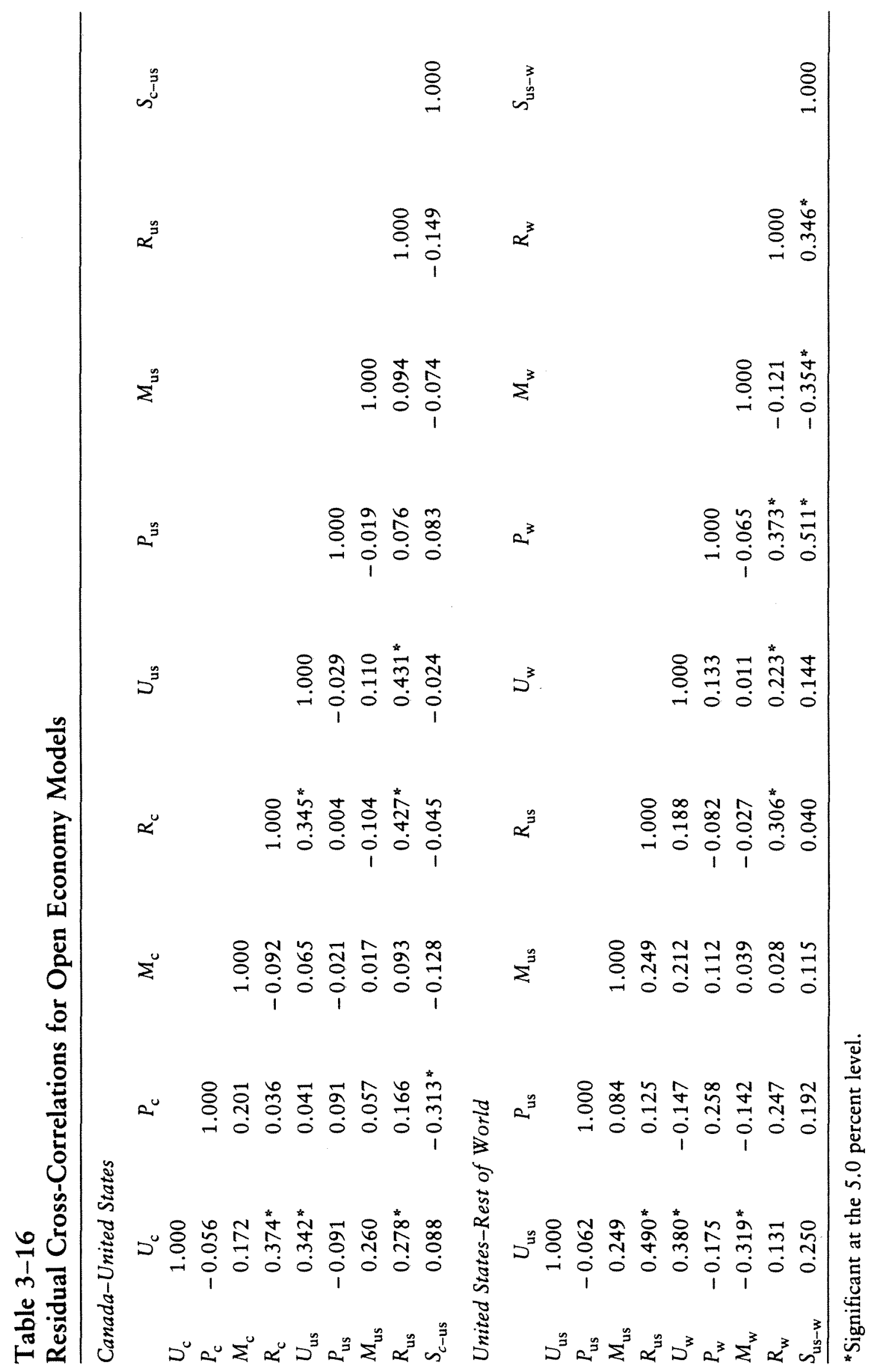




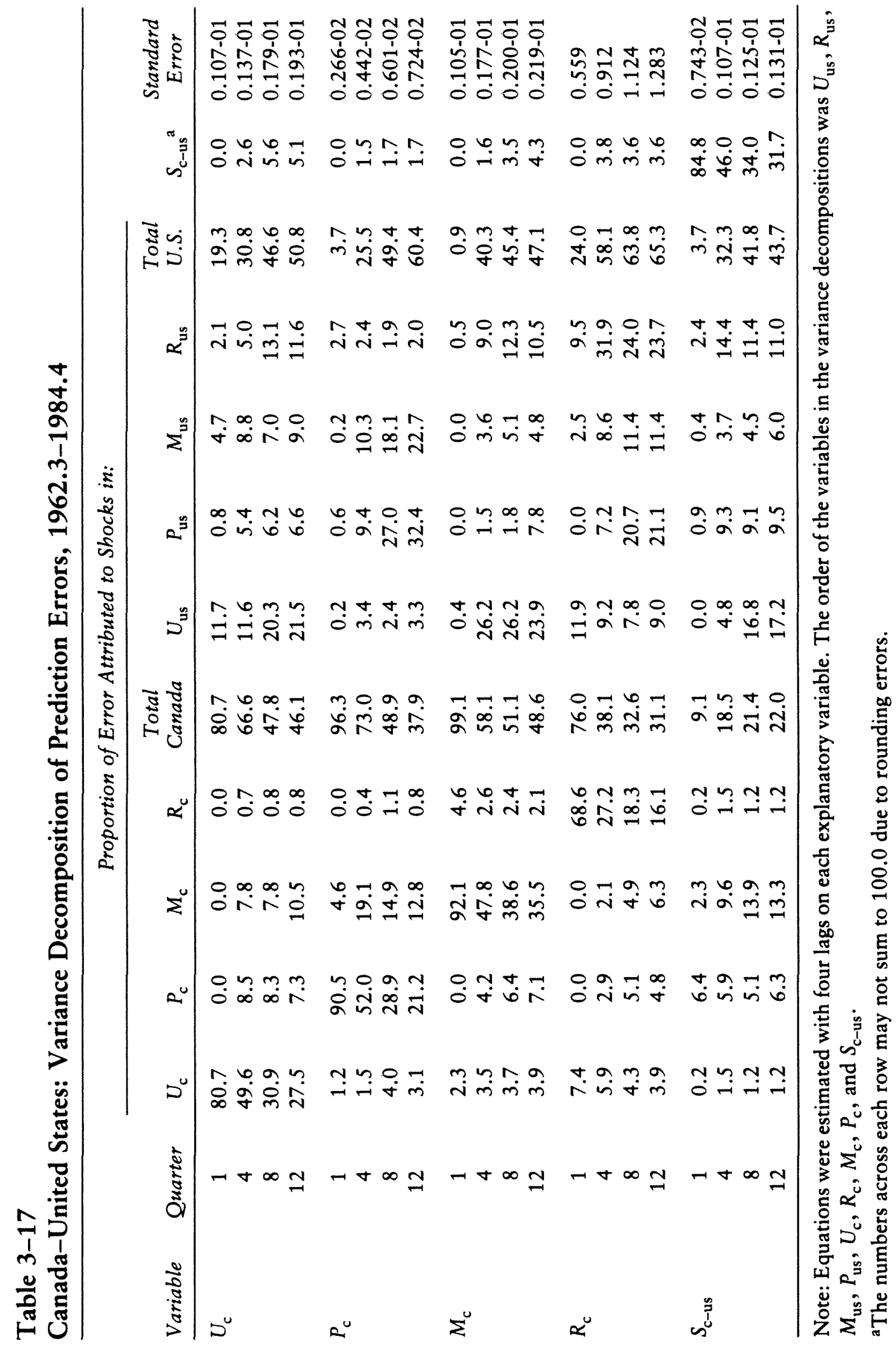




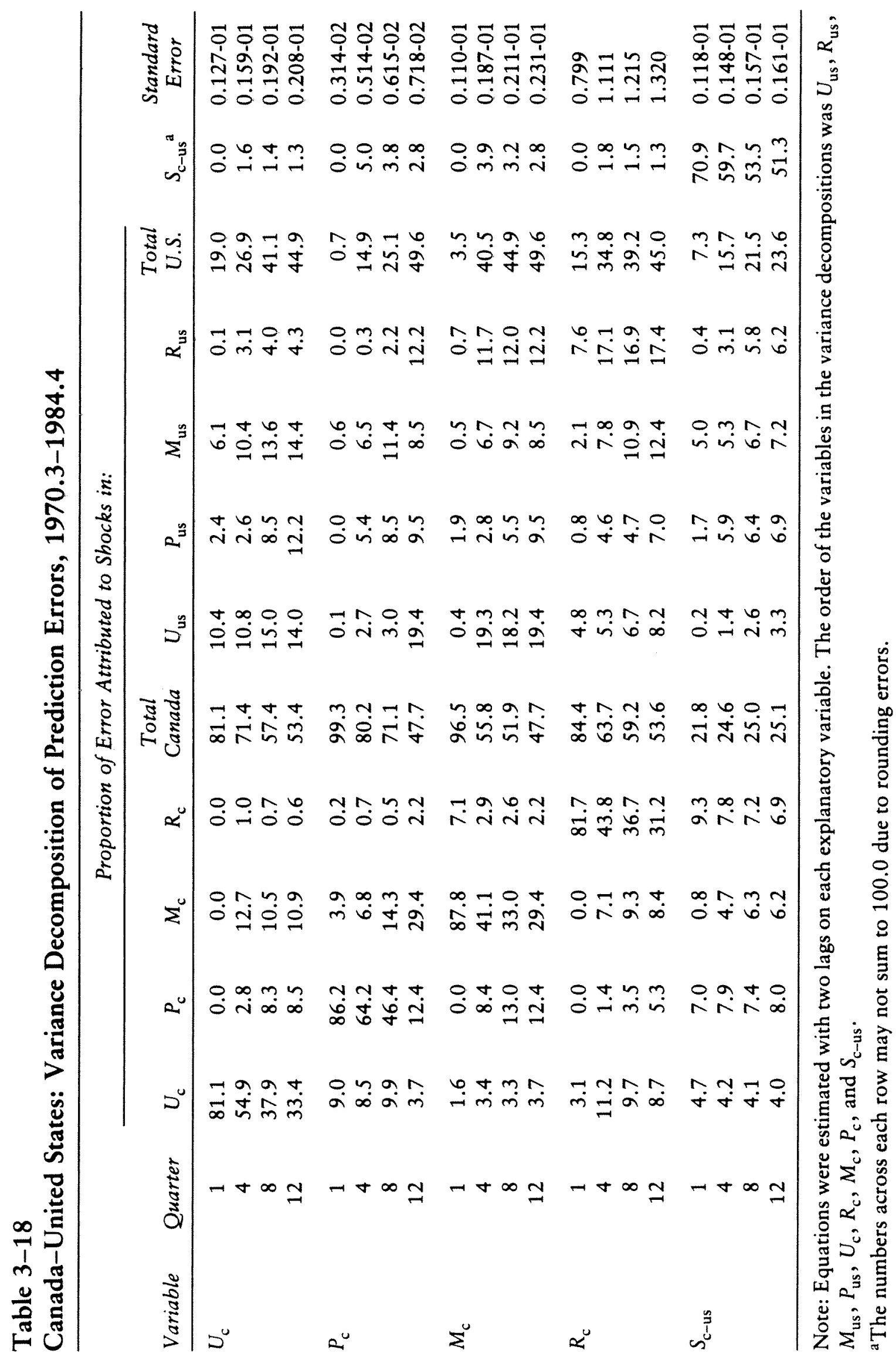




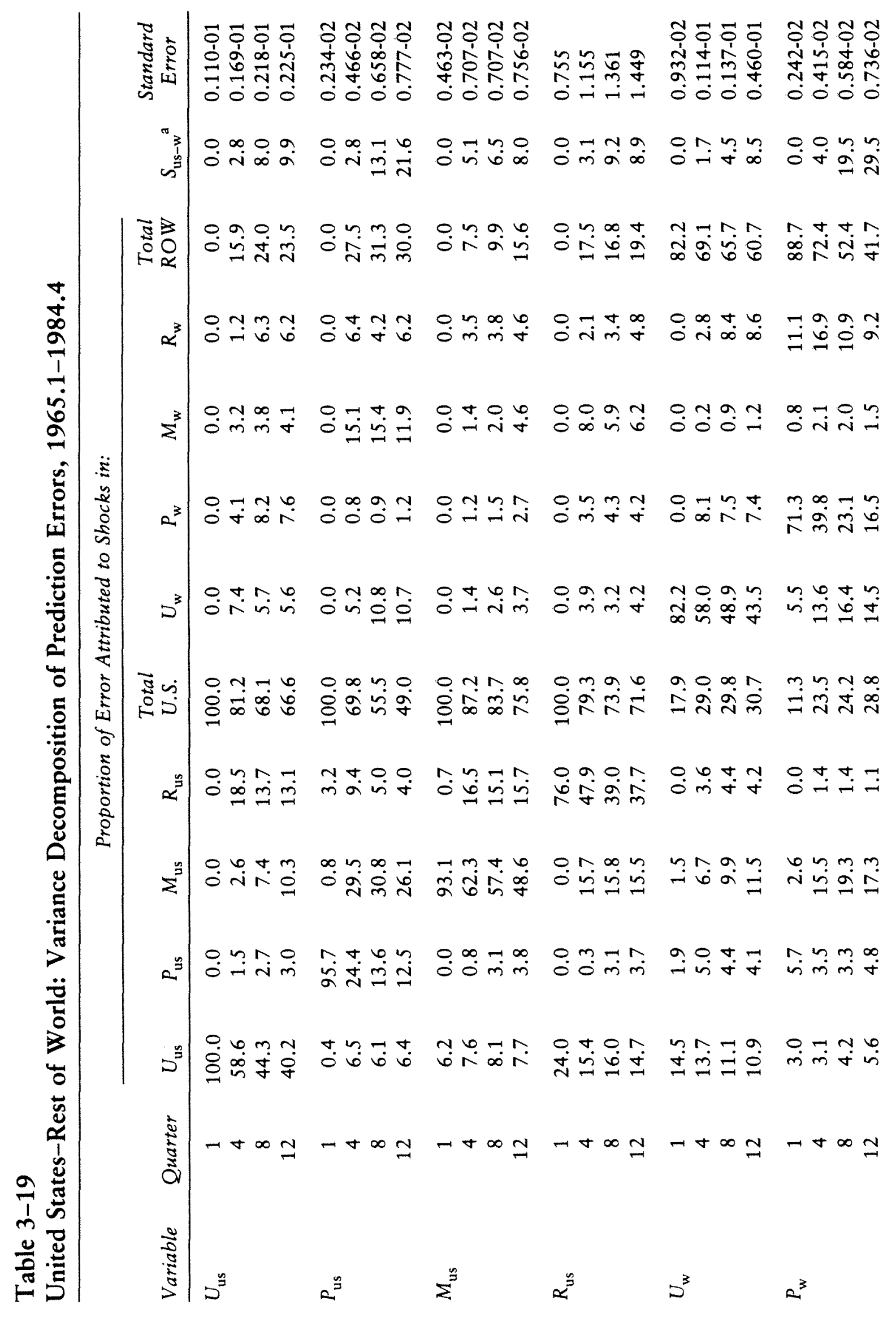




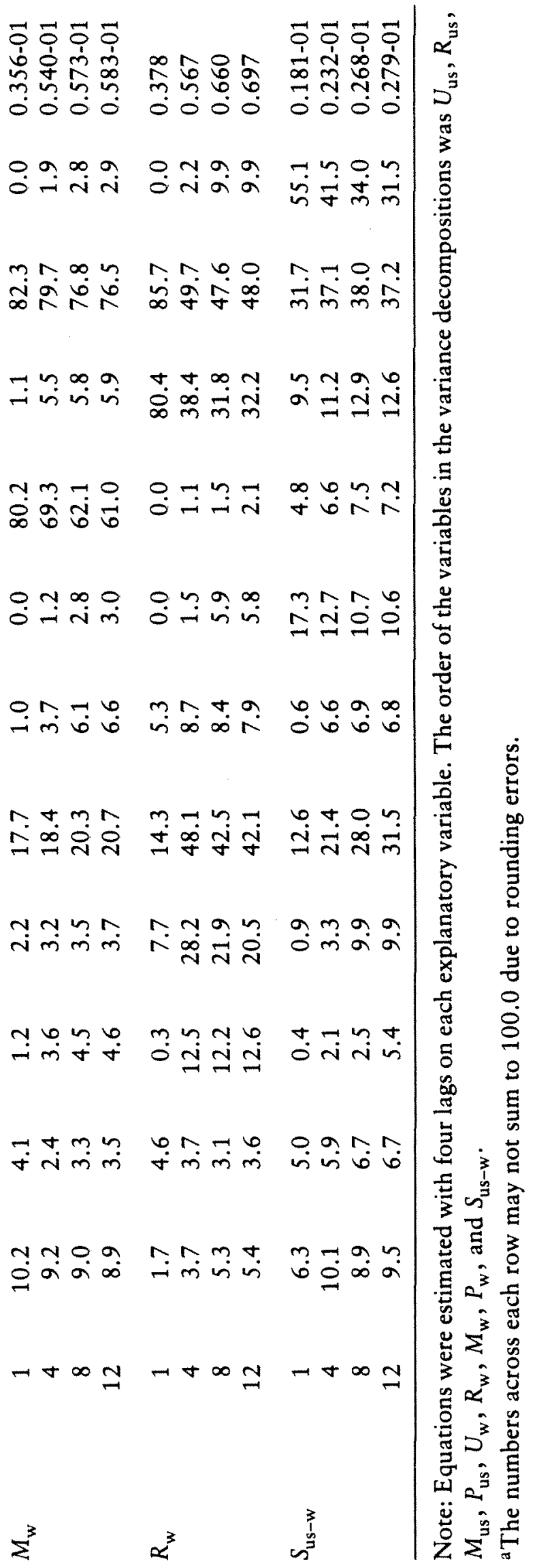




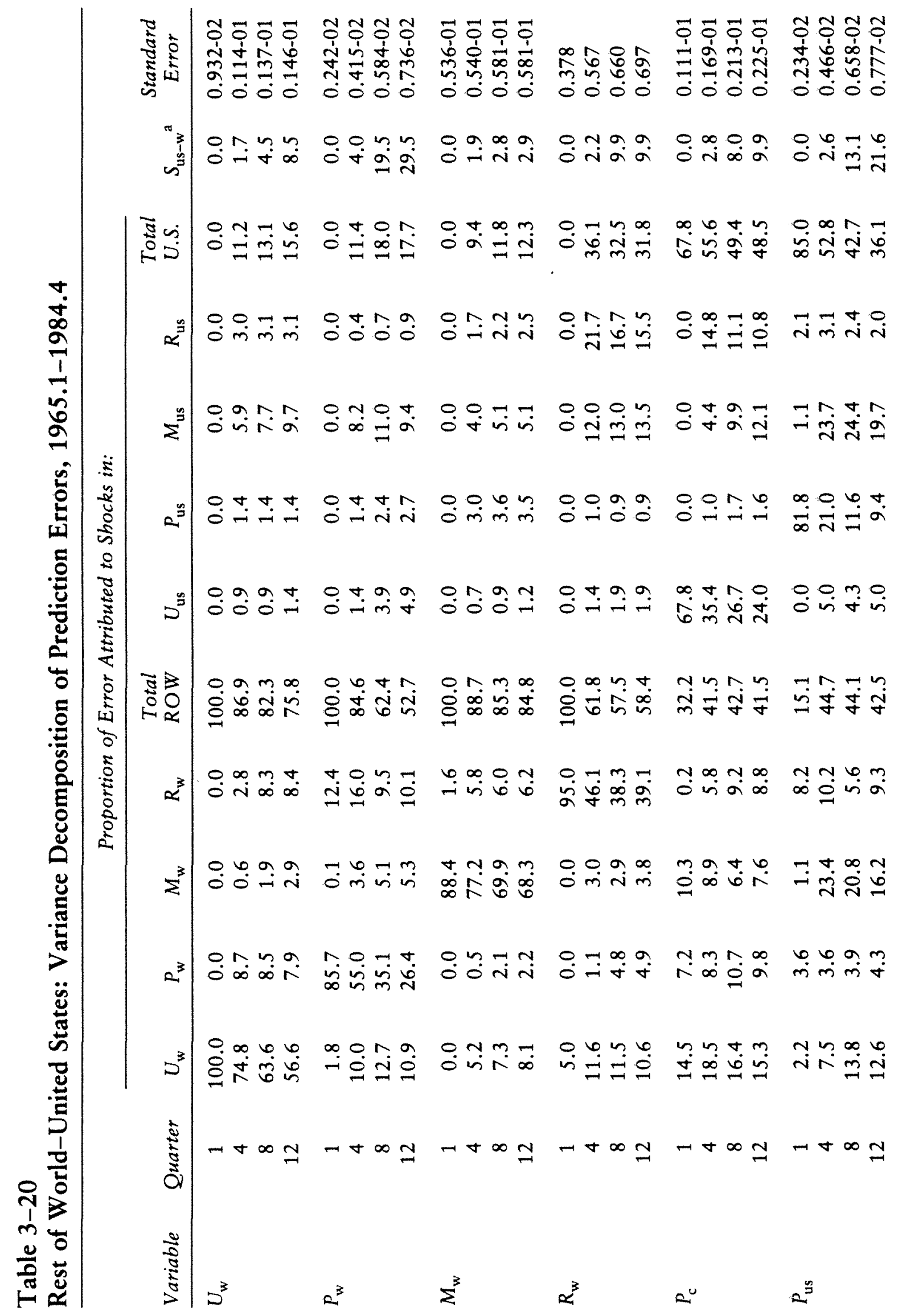




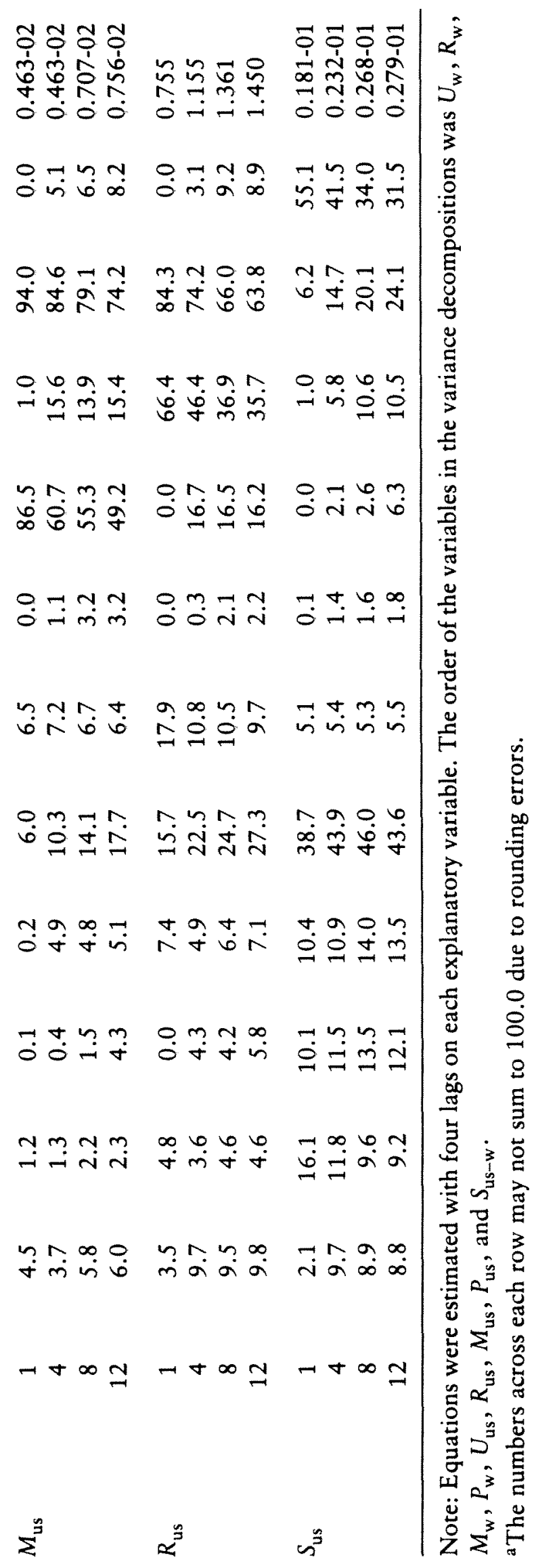


The impulse response functions for the open economy models provide a convenient and often more effective means of presenting many of the results described above. Since it is impossible to examine all of the variable combinations that are contained in tables 3-17 through 3-20, we will concentrate on the impulse responses of the Canadian and U.S. money equations. The differences observed in their responses will give some idea of the extent to which monetary policy might have been affected by international influences in the two countries.

Figure 3-5 compares the responses of Canadian (----) and U.S. (-.-.) money to five foreign shocks. With the exception of the exchange rate shocks the response of Canadian money is always much larger than that of U.S. money. Because these responses are based on the full sample estimates of the Canadian and U.S. models, one might suspect that the results have been biased by Canada's experience during the fixed exchange rate period. However, the same response patterns are observed in figure 3-6 when the shocks are rerun on data drawn exclusively from the flexible exchange period, 1970.3-1984.4.

The sensitivity of Canadian money to foreign shocks seems to be significantly greater than that of U.S. money. Figures 3-7 and 3-8 present the impulse responses of Canadian and U.S. money to domestic shocks, in both closed and open economy models. While the introduction of foreign variables has greatly reduced the influence of $R_{\mathrm{c}}, U_{\mathrm{c}}$, and $P_{\mathrm{c}}$ on Canadian money, the response of U.S. money to $R_{\mathrm{us}}, U_{\mathrm{us}}$, and $P_{\mathrm{us}}$ has remained virtually unchanged. Evidently, foreign shocks have not affected U.S. financial markets to the same extent as those in Canada, although several foreign variables enter the U.S. money and interest rate equations with significant coefficients.

\section{Policy Implications}

Vector autoregressions are by their nature ill-suited to detailed policy analysis. They are useful descriptive devices that capture the major trends and relationships in economic time series, and that serve as useful checks on other, more structured, modeling procedures. It is therefore difficult to draw any strong conclusions about the causes and consequences of the international relationships identified in the open economy models here. Nevertheless, by combining some institutional knowledge with the results of this empirical analysis, it may be possible to draw some tentative conclusions regarding the importance of economic interdependence from a Canadian perspective.

Narrowly interpreted, the results of subsection Open Economy Models would suggest that the behavior of the Canadian economy is largely determined by U.S. variables and that independent macro policies have not played 
a significant role in either fixed or flexible exchange rate periods. Though one would not want to minimize the importance of open economy considerations in a country such as Canada, researchers may be faced with an "observational equivalence problem" when they try to interpret these results. More specifically, the coincident movement of Canadian and U.S. macro variables may owe as much to the shared policy objectives of U.S. and Canadian monetary authorities as it does to the strong structural relationships binding the two economies. Canadian and U.S. policymakers have typically interpreted economic events in a similar fashion and have often held similar views with regard to what policy actions were appropriate in a given situation. These policy considerations have no doubt contributed to the significance of U.S. variables in the Canadian equations here. Their signficance has also been reinforced by the reaction of Canadian policymakers to short-run movements in U.S. interest rates and attendant fluctuations in the Canadian-U.S. exchange rates.

Research at the Bank of Canada and elsewhere has tended to confirm the impressions of many central bankers that exchange rate markets are subject to "bandwagon" effects and often appear to be driven by extrapolative expectations. ${ }^{29}$ In a technical sense, the markets are "irrational" and/or inefficient. This has given rise over the years to a policy reaction on the part of the Bank of Canada in which short-term exchange rate pressures caused by changes in U.S. interest rates are partially resisted by similar movements in Canadian rates. This policy is not intended to peg the exchange rate or to maintain it at an artificial level, but merely to limit the amount of overshooting, though obviously it may be difficult for observers to distinguish between these two types of policies.

This response to exchange rate fluctuations is believed to be desirable for two reasons. First, the exchange rate is an important price in an open economy like Canada and unnecessary volatility could have serious consequences on efficiency. Second, in the inflationary environment of the 1970s and early 1980 s, there was concern that "unwarranted" exchange rate movements (depreciations) could fuel inflation expectations.

It is worth noting that this strategy of "short-circuiting" movements in exchange rates and domestic prices with offsetting changes in interest rates was not inconsistent with the Bank's policy of monetary targeting. Rather, it was viewed as a complementary response, helping to keep $M-1$ on target through much of the $1975-81$ period. ${ }^{30}$

Over the long run many of the problems that Canada has experienced in the conduct of monetary policy have been domestic in origin rather than international. These include misperceptions concerning the natural rate of unemployment and the unsettling effects of financial innovations on Canadian money demand. One important recent exception occurred during the 1984 period of high world interest rates when attempts to moderate the 
118 - How Open Is the U.S. Economy?
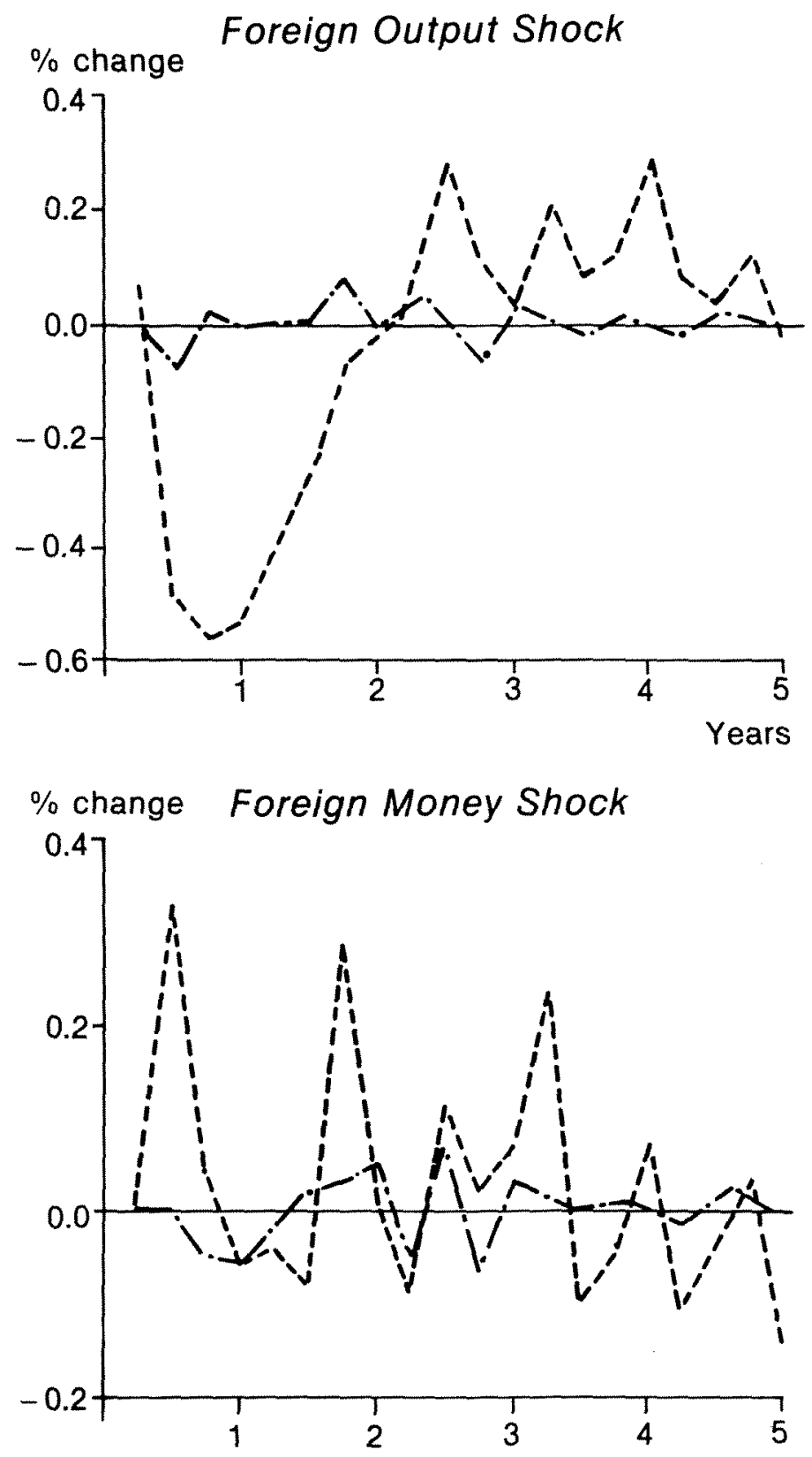

$\begin{array}{ll}-\cdots-\cdots & \text { Canadian money } \\ -\cdots-\cdots & \text { U.S. money }\end{array}$

Figure 3-5. Response in Canadian and U.S. Money to Foreign Shocks 

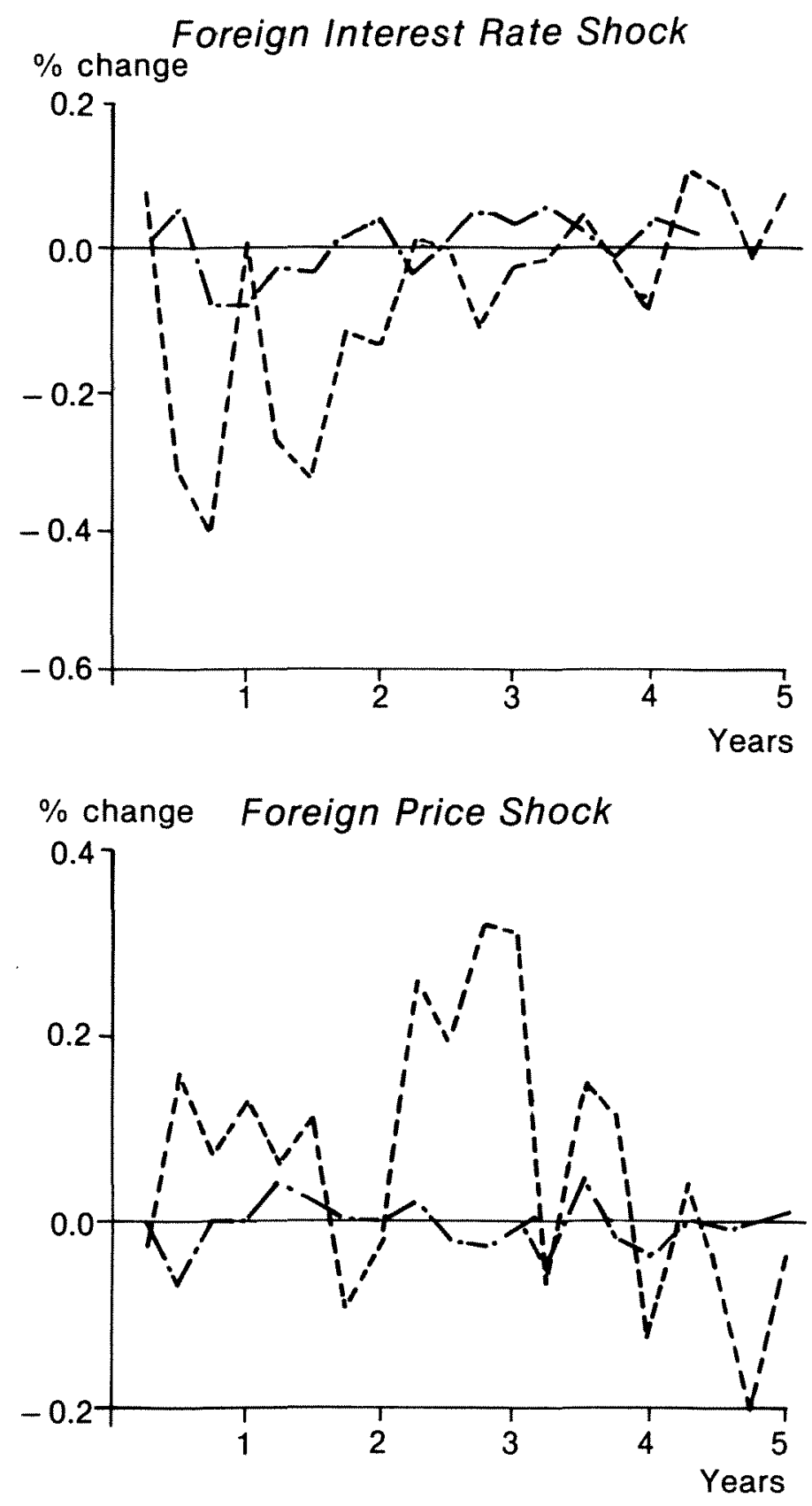

\% change Exchange Rate Shock

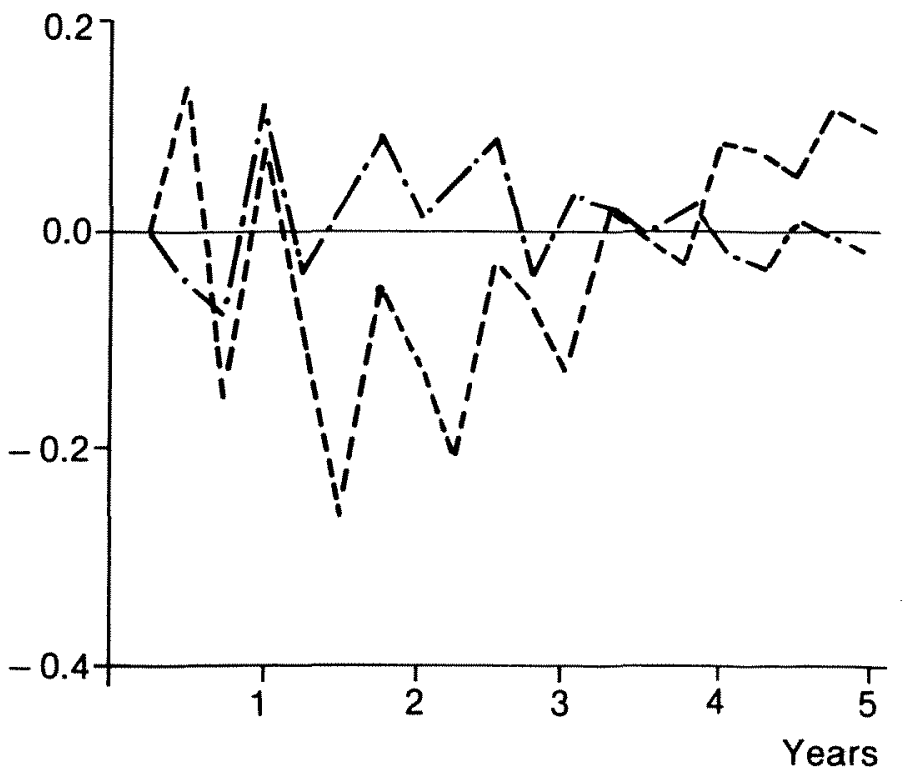


120 - How Open Is the U.S. Economy?
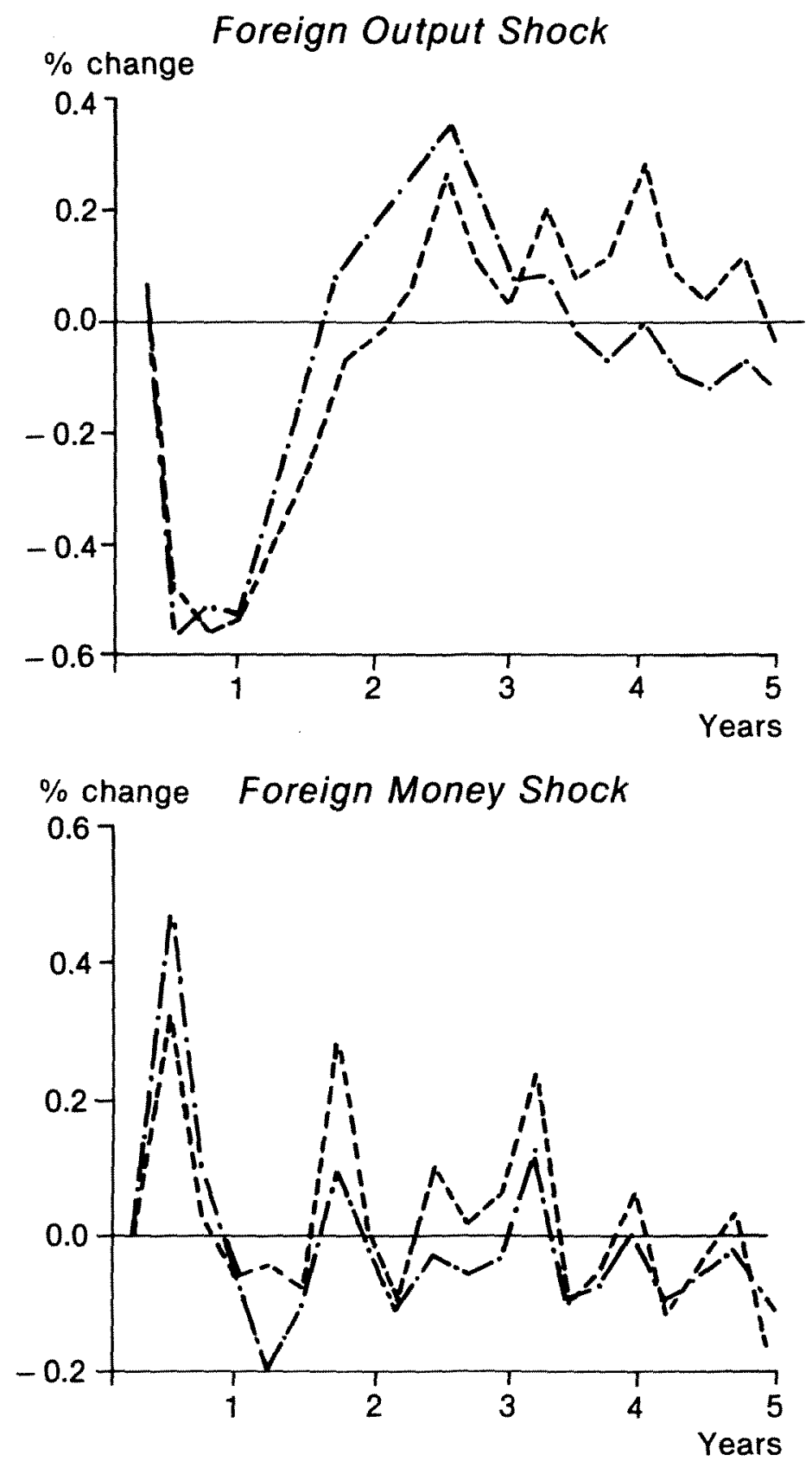

$\begin{array}{ll}\cdots & \text { Open } \\ \cdots-\cdots & \text { Floating }\end{array}$

Figure 3-6. Response in Canadian Money to Foreign Shocks 

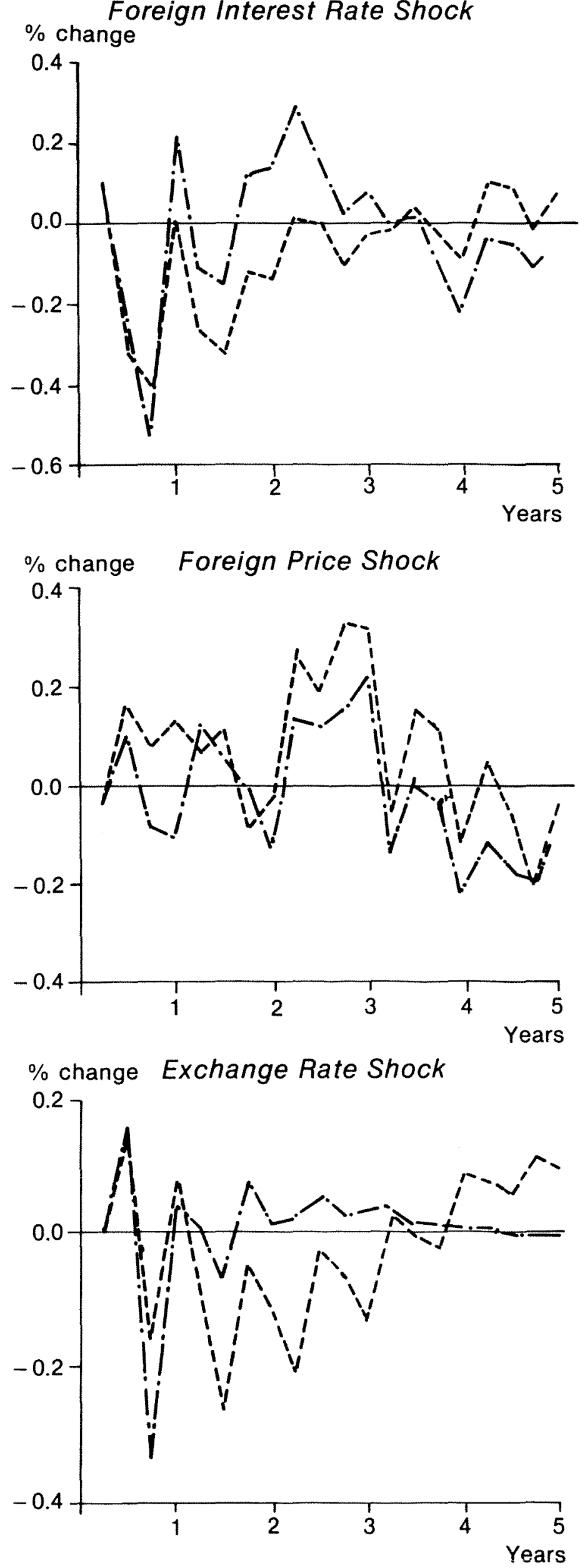

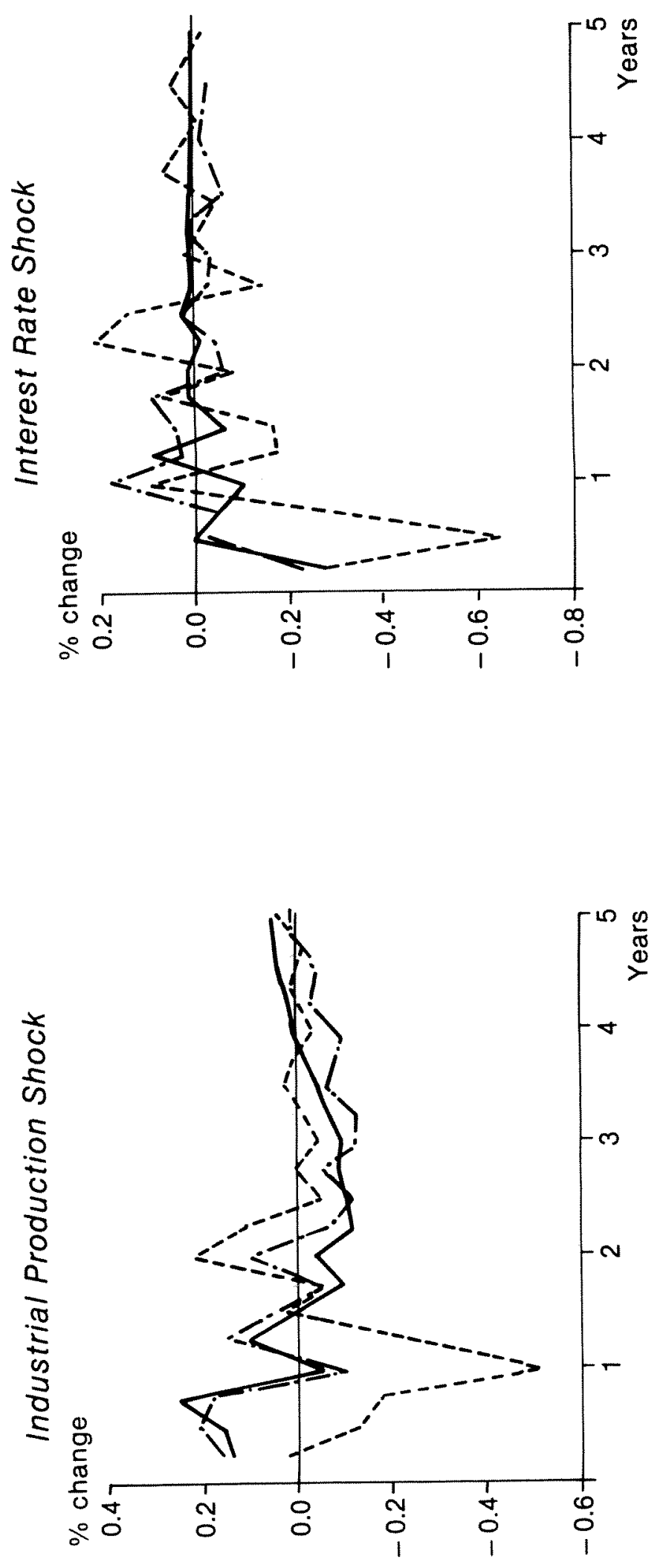


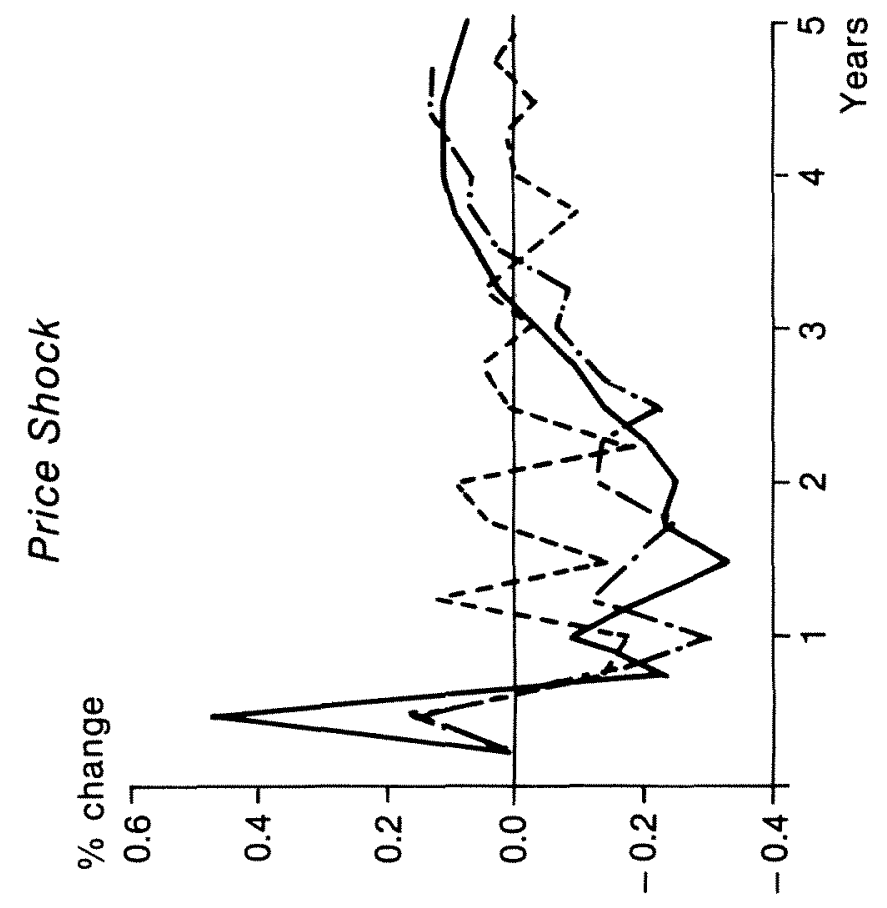

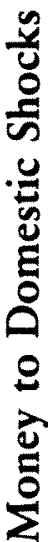

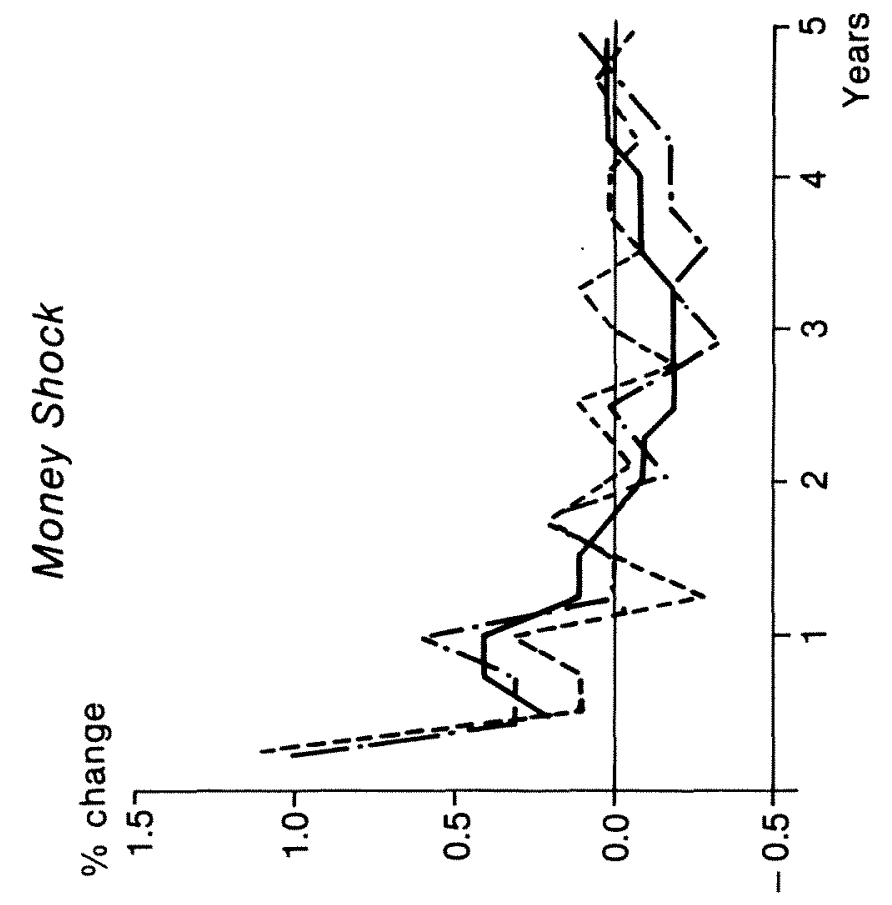

롫

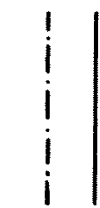


124 - How Open Is the U.S. Economy?
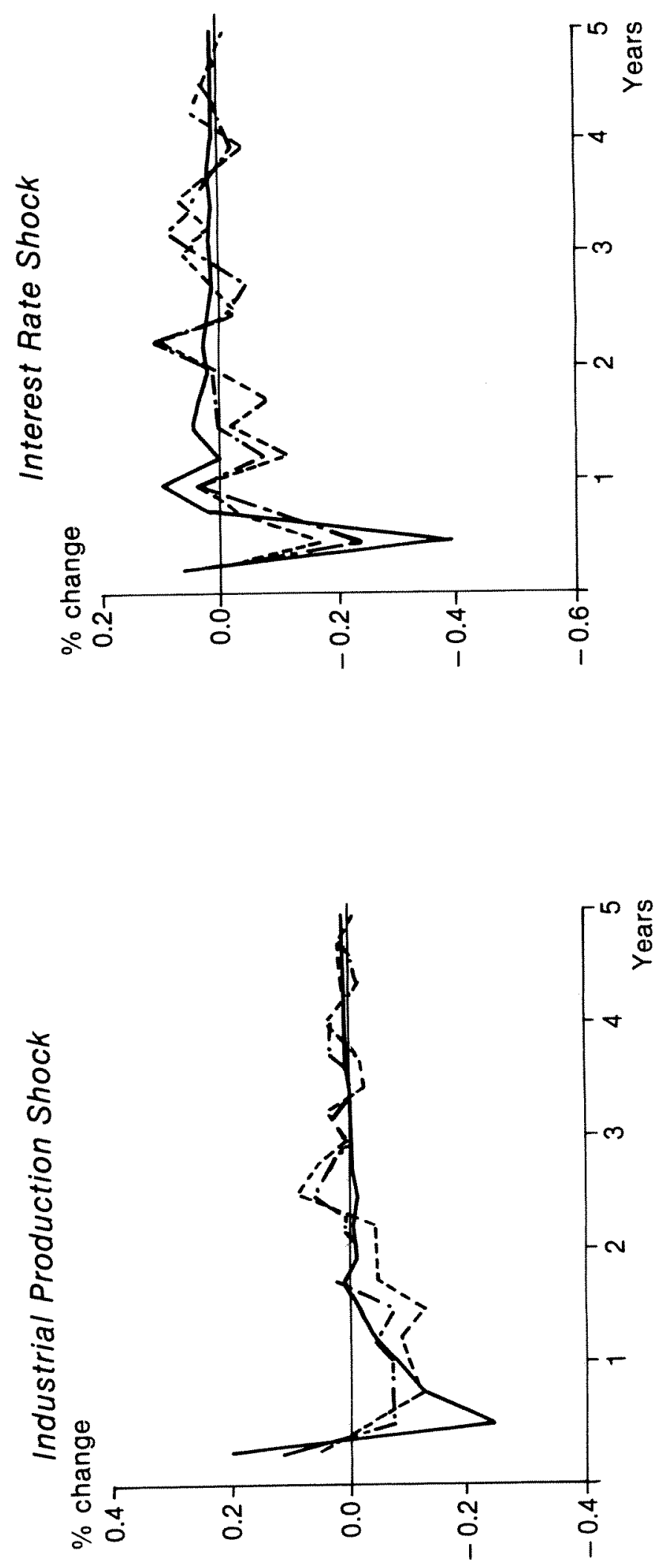


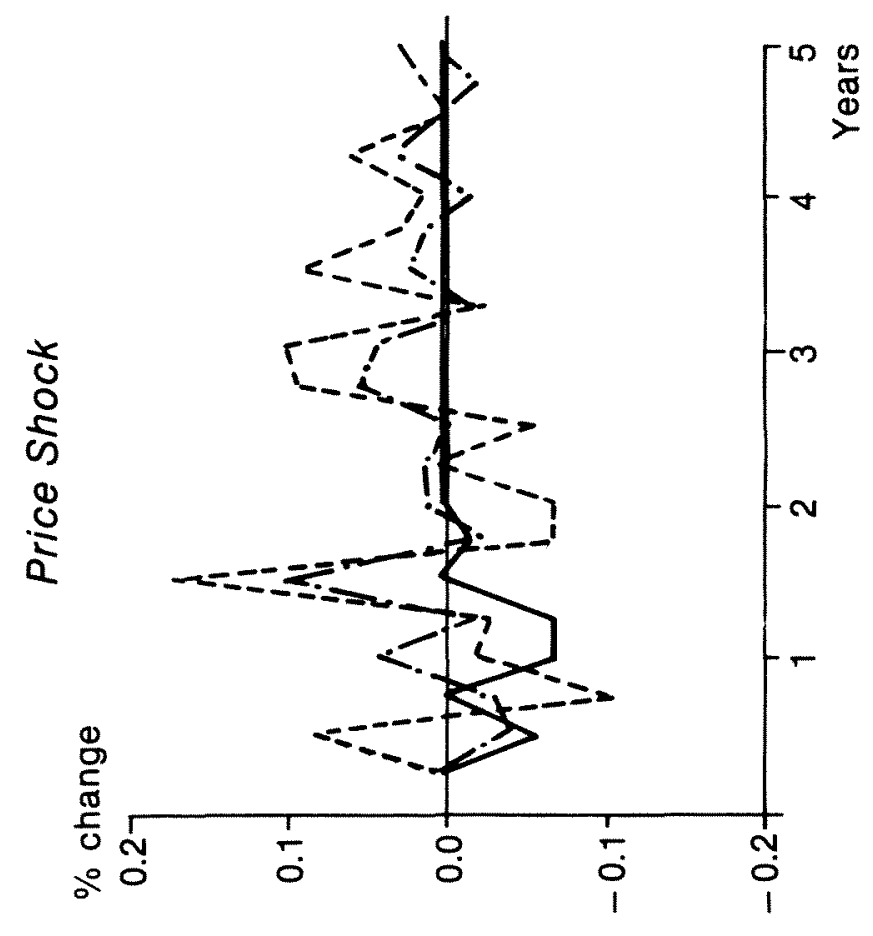

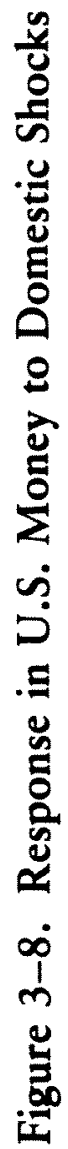
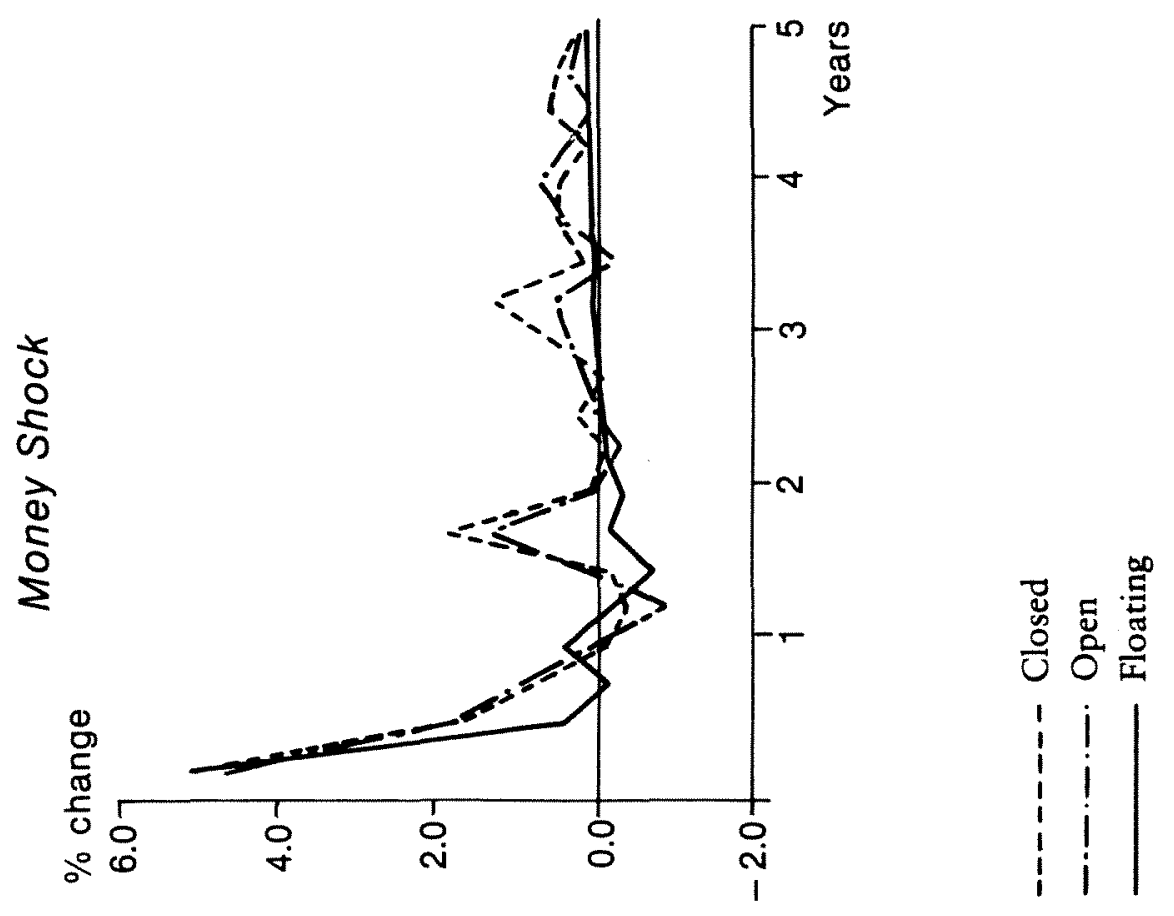
upward movement in Canadian interest rates were frustrated by the reactions of agents in international money markets. This episode can also be linked to domestic policy problems, however. The Bank of Canada had been forced to abandon its $M-1$ targets in November 1982, as financial innovations had made $M-1$ an unreliable indicator of the ease of restrictiveness of monetary policy. Without a nominal anchor to condition their expectations, market views of future values of the exchange rate were not held with confidence, causing domestic interest rates to rise and the exchange rate to fall. ${ }^{31}$

To summarize, the policy options of a small open economy may not be as circumscribed as the earlier empirical evidence would indicate. Though greater economic integration and international capital mobility occasionally lead to policy complications, monetary policy remains a potent tool whose effectiveness under normal conditions has probably been enhanced (à la Mundell) rather than diminished by the near perfect substitutability of Canadian and U.S. financial instruments. International economic interdependence need not preclude independent policy action by small open economies such as Canada.

\section{Conclusion}

Few readers will find the Results section surprising or controversial. With the possible exception of the structural stability tests, the evidence is consistent with most of our priors. The primary contribution of this chapter has been to apply VAR modeling techniques to the study of economic interdependence and to quantify some of the concepts and relationships that have heretofore only been discussed in general qualitative terms.

The Results section highlighted the differences between small (dependent) economies such as Canada and large (interdependent) economies such as the United States. The Policy Implications section tried to show how goal and policy interdependence might have contributed to the strong causal relationships that are observed between Canada and the United States.

Many of these results have been anticipated by earlier papers, but these studies typically offered a partial analysis directed at only one or two variables such as inflation and money. ${ }^{32}$ The present chapter has taken a more comprehensive view of interdependence, but has obviously sacrificed some important details and structure in the process. We hope to extend our results in the future by substituting alternative proxies for some of the foreign variables in our regressions and rerunning our models on monthly data. Higher frequency data would allow us to examine the short-run dynamics of our models in greater detail and would provide more degrees of freedom if shorter lag lengths were accepted in the monthly specifications. This in turn would improve the efficiency of our estimates and allow us to experiment with additional variables, including improved fiscal proxies. 


\section{Notes}

1. The G-7 includes: Canada, France, Germany, Italy, Japan, the United Kingdom, and the United States.

2. See for example Gordon and King (1982) or Offenbacher and Porter (1983).

3. A fifth variable, the nominal value of government debt, was included in some of our preliminary work in an effort to identify the separate effects of monetary and fiscal policies. Unfortunately the addition of this fiscal proxy led to problems of collinearity and significantly reduced the available degrees of freedom, making it difficult to obtain reasonable parameter estimates on other more important variables. Since likelihood ratio tests indicated that government debt was statistically insignificant in all three models, we decided to exclude it in subsequent runs.

4. As shall be seen later, this is only true in the estimation stage of the analysis. It is necessary to make some implicit assumptions about the causal relationships of the variables when the impulse responses and variance decompositions of the models are examined.

5. $j$ is the number of endogenous variables originally in the model and $n$ is the lag length on each variable on the right-hand side.

6. Most of the data were taken from the OECD publication, Main Economic Indicators and the Bank for International Settlement (BIS) databank.

7. The consumer price index for the United States is defined exclusive of housing costs.

8. Notice that the indexes for the rest of the world (ROW) have been defined from a U.S. perspective (one including all countries in the G-7 except the United States), since these indexes' primary purpose is to serve as foreign variables in the open economy model of the United States.

9. Masson and Blundell-Wignall (1984) have constructed similar proxies for ROW using a more comprehensive weighting scheme which ranks the countries in terms of their contribution to world trade and international financial flows. The weights that they obtain from this more involved procedure are very close to the averages reported in the table.

10. The one exception was interest rates which were simply first differenced.

11. See also Nelson and Kang (1984).

12. The test statistic is distributed as $\chi^{2}(r)$ and is computed as

$$
V=(T-c)\left[\log \left|\mathbf{\Omega}^{\mathrm{R}}\right|-\log \left|\mathbf{\Omega}^{\mathrm{U}}\right|\right]
$$

where $T$ is the number of observations, $c$ is the number of parameters in the unrestricted model, $\left|\Omega^{\mathrm{R}}\right|$ and $\left|\mathbf{\Omega}^{\mathrm{U}}\right|$ are the determinants of the covariance matrices of the restricted and unrestricted models, and $r$ is the number of restrictions.

13. The Canadian regressions, unlike those for the United States, begin in 1962.3 rather than 1962.1. This was done in order to avoid the instability associated with Canada's 1961-62 exchange rate crisis and the uneasy transition from flexible to fixed exchange rates that followed.

14. The negative signs on lagged inflation are not surprising given the supply shocks of the 1970s. The same effects are observed, however, when the equations are run on pre-1973 data.

15. Financial innovations that have recently lowered the demand for transactions 
balances in Canada could be responsible for the negative sign on $U_{c}$. See Freedman (1983). This result disappears, however, once foreign variables are added to the model in the section Open Economy Models.

16. Contrary to the results reported by Sims (1980a), interest rates and money have almost identical weights in the variance decompositions of U.S. output. Sims' use of monthly numbers and the substitution of 30-day treasury bill rates for the call loan rate could account for this difference.

17. The same "perverse" initial responses to innovations in $R_{\mathrm{us}}$ and $P_{\mathrm{us}}$ have been reported by Litterman and Weiss (1983).

18. The Canadian authorities, they claim, were able to maintain tight control over aggregate $M-1$ through relatively minor adjustments in Canadian short-term interest rates because of the high interest elasticity of Canadian money demand. See also Thiessen (1982).

19. The foreign variables for $U, P, M$, and $R$ in the Canadian and ROW models are proxied by U.S. output, prices, money, and interest rates. In the U.S. model, these foreign variables are proxied by the aggregate indexes which were constructed for ROW. $S_{\mathrm{c}-\mathrm{us}}$, the exchange rate in the Canadian model, is the U.S. dollar price of one Canadian dollar. $S_{\mathrm{us}-\mathrm{w}}$, the exchange rate in the U.S. and ROW models, is the ROW price of one U.S. dollar.

20. Suspecting that this result might have been caused by our choice of interest rates, we reran the Canadian money equation with treasury bill rates and ninety-day commercial paper rates substituted for the call loan rate. The same results were obtained in every case.

21. Canadian policymakers have never considered sterilized intervention to be a viable policy option, except in the very short run, as Canadian and U.S. securities are believed to be almost perfect substitutes. See Boothe et al. (1985) and Freedman (1982).

22. Longworth et al. (1983), Boothe (1983), and Longworth (1985).

23. There is a possibility that the test statistics are biased toward false "nonrejection" of the stability hypothesis because of the limited number of observations included in each subperiod. However, Litterman and Weiss $(1983$, p. 7) claim that the bias produced by a low "observation-to-parameter ratio" actually runs in the opposite direction and favors false rejection.

24. Certain Canadian variables did have significant explanatory power in the U.S. equations. Lagged values of $M_{c}$, for example, seemed to be a reliable leading indicator of U.S. output. Taken as a group, however, the Canadian variables were insignificant.

25. See Alexander (1981), McKinnon (1982), Miles (1978), and Poloz (1982).

26. See Courchene $(1976,1981)$ and Bordo and Choudhri (1982).

27. See Cooper (1985).

28. The proportions that are assigned to each country are sensitive to the order in which the countries appear, but the qualitative results in tables 3-19 and 3-20 are generally consistent.

29. See Boothe (1983) and Longworth (1985).

30. A more detailed discussion of the short-circuiting concept is contained in Freedman (1982).

31. Bank of Canada: Annual Report, 1984. 
32. See for example Batten and Ott (1985), Bordo and Choudhri (1982), Choudhri (1983), and Burbidge and Harrison (1983).

\section{References}

Abrams, R.K., and G.H. Sellon. "Monetary Control: A Comparison of the U.S. and Canadian Experiences, 1975-1979." Mimeo, International Monetary Fund, December 1983.

Alexander, W.E. 'Foreign Influences on the Demand for Money in an Open Economy: The Canadian Case." Monetaria 4, no. 1, January/March 1981, pp. 17-38.

Bank of Canada. Annual Report, 1984.

Batten, D.S., and R.W. Hafer. "Currency Substitution and the Link between Money and GNP in the U.S.: 1972-83." Mimeo, Federal Reserve Bank of St. Louis, 1984.

Batten, D.S., and R.W. Hafer. "The Impact of International Factors on U.S. Inflation: An Empirical Test of the Currency Substitution Hypothesis." Southern Economic Journal, forthcoming 1986.

Batten, D.S., and M. Ott. "The Interrelationship of Monetary Policies under Floating Exchange Rates." Journal of Money, Credit, and Banking 17, no. 1, February 1985, pp. 103-10.

Batten, D.S., and D.L. Thorton. "Lag-Length Selection and Tests of Granger Causality between Money and Income." Journal of Money, Credit, and Banking 37, no. 2, May 1985, pp. 164-78.

Boothe, P.M. "Speculative Profit Opportunities in the Canadian Foreign Exchange Market, 1974-78." Canadian Journal of Economics 16, no. 4, November 1983, pp. 603-11.

Boothe, P.M., K. Clinton, Agathe Côté, and D. Longworth. International Asset Substitutability: Theory and Evidence for Canada. Bank of Canada, February, 1985.

Bordo, M.D., and E.U. Choudhri. "The Link between Money and Prices in an Open Economy: The Canadian Evidence from 1971 to 1980." Review, Federal Reserve Bank of St. Louis 64, no. 7, August-September 1982, pp. 13-23.

Burbidge, J., and A. Harrison. "(Innovation) Accounting for U.S.-Canada Business Cycles." Mimeo, McMaster University, April 1983.

Choudri, E.U. "The Transmission of Inflation in a Small Economy: An Empirical Analysis of the Influence of U.S. Monetary Disturbances on Canadian Inflation, 1962-80." Journal of International Money and Finance 2, 1983, pp. 167-78.

Cooper, R.N. "Economic Interdependence and Coordination of Economic Policies." In Handbook of International Economics, vol. 2, R.W. Jones and P.B. Kenen (eds.), 1985, pp. 1195-234.

Courchene, T.J. Money, Inflation, and the Bank of Canada: An Analysis of Canadian Monetary Policy from 1970 to Early 1975. Montreal: C.D. Howe Research Institute, 1976.

- Money Inflation and the Bank of Canada, Vol. 2: An Analysis of Monetary Gradualism, 1975-80. Montreal: C.D. Howe Research Institute, 1981. 
Daniel, B.C., and H.O. Fried. "Currency Substitution, Postal Strikes and Canadian Money Demand." Canadian Journal of Economics 16, no. 4, November 1983, pp. 112-24.

Dickey, D.A., and W.A. Fuller. "Distribution for the Estimators for Autoregression Time Series with a Unit Root." Journal of the American Statistical Association 74, pp. 427-31.

Doan, T., and R. Litterman. User's Manual RATS Version 4.v., VAR Econometrics, 1980.

Driskill, R.A., and S.M. Sheffrin. “'The Patman Effect' and Stabilization Policy." The Quarterly Journal of Econometrics, February 1985, pp. 145-63.

Fackler, J.S. "An Empirical Analysis of the Markets for Goods, Money, and Credit." Journal of Money, Banking, and Credit 37, no. 1, February 1985, pp. 28-42.

Freedman, C. "The Effect of U.S. Policies on Foreign Countries: The Case of Canada." In Monetary Policy Issues in the 1980's. Kansas City: Federal Reserve Bank of Kansas City, 1982, pp. 97-118.

- "Financial Innovation in Canada: Causes and Consequences." American Economic Review 73, no. 2, May 1983, pp. 101-6.

Freeman, G. "International Inflation: Four Commentaries." Economic Perspectives. Federal Reserve Bank of Chicago, July 1984.

Gordon, R.J., and S.R. King. "The Output Cost of Disinflation in Traditional and Vector Autoregressive Models." Brookings Papers on Economic Activity 1, 1982, pp. 205-42.

Litterman, R.B., and L. Weiss. "Money, Real Interest Rates, and Output: A Reinterpretation of Postwar U.S. Data." National Bureau of Economic Research Working Paper no. 1077, February 1983.

Longworth, D. "Exchange Market Efficiency." Economic Letters 8, nos. 2 and 3, 1985, pp. 247-49.

Longworth, D., P.M. Boothe, and K. Clinton. A Study of the Efficiency of Foreign Exchange Markets. Bank of Canada, October 1983.

Masson, P., and A. Blundell-Wignall. "Fiscal Policy and the Exchange Rate in the Big Seven: Transmission of U.S. Fiscal Shocks." Mimeo, OECD, May 1984.

McKinnon, R.I. "Currency Substitution and Instability in the World Dollar Standard." American Economic Review 72, no. 3, June 1982, pp. 320-33.

Miles, M. "Currency Substitution, Flexible Exchange Rates, and Monetary Independence." American Economic Review, 68, no. 3, June 1978, pp. 428-36.

Nelson, C.R., and H. Kang. "Pitfalls in the Use of Time as an Explanatory Variable in Regressions." Journal of Business and Economic Statistics 2, no. 1, January 1984, pp. 73-82.

Nelson, C.R., and C.I. Plosser. "Trends and Random Walks in Macroeconomic Time Series: Some Evidence and Implications." Journal of Monetary Economics 10, pp. 139-62.

Offenbacher, E.K., and R.D. Porter. "Empirical Comparisons of Credit and Monetary Aggregates Using Vector Autoregression Methods." Special Studies Paper no. 181, Federal Reserve Board, Washington, D.C., October 1983.

Poloz, S. "Unstable Velocity, Volatile Exchange Rates, and Currency Substitution: The Demand for Money in a Multicurrency World." Unpublished doctoral thesis, University of Western Ontario, 1982. 
Sims, C.A. "Comparison of Interwar and Postwar Cycles: Monetarism Reconsidered." American Economic Review 70, 1980a, pp. 250-57.

Sims, C.A. "Macroeconomics and Reality." Econometrica 48, 1980b, pp. 1-48.

Thiessen, G.G. "The Canadian Experience with Monetary Targeting." In Central Bank Views on Monetary Targeting. New York: Federal Reserve Bank of New York, May 1982, pp. 100-5. 